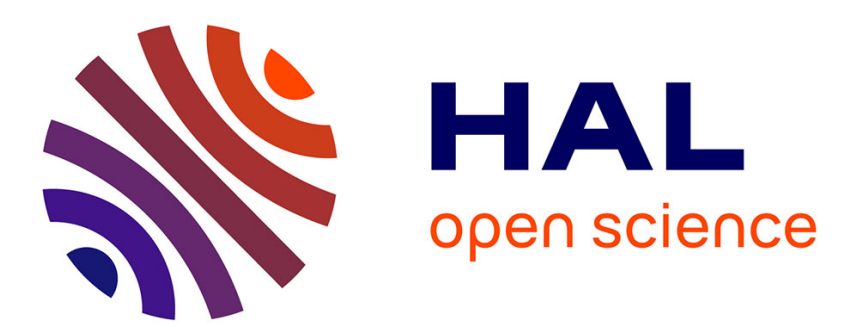

\title{
Mobile Spatial coordinate Measuring System (MScMS) - Introduction to the system
}

Fiorenzo Franceschini, Maurizio Galetto, Domenico Maisano, Luca

Mastrogiacomo

\section{- To cite this version:}

Fiorenzo Franceschini, Maurizio Galetto, Domenico Maisano, Luca Mastrogiacomo. Mobile Spatial coordinate Measuring System (MScMS) - Introduction to the system. International Journal of Production Research, 2009, 47 (14), pp.3867-3889. 10.1080/00207540701881852 . hal-00513024

\section{HAL Id: hal-00513024 \\ https://hal.science/hal-00513024}

Submitted on 1 Sep 2010

HAL is a multi-disciplinary open access archive for the deposit and dissemination of scientific research documents, whether they are published or not. The documents may come from teaching and research institutions in France or abroad, or from public or private research centers.
L'archive ouverte pluridisciplinaire HAL, est destinée au dépôt et à la diffusion de documents scientifiques de niveau recherche, publiés ou non, émanant des établissements d'enseignement et de recherche français ou étrangers, des laboratoires publics ou privés. 


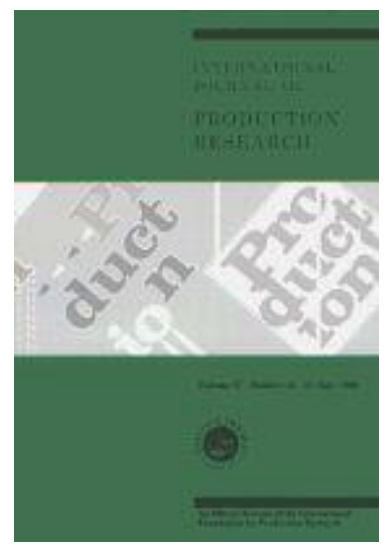

Mobile Spatial coordinate Measuring System (MScMS) $\square$ Introduction to the system

\begin{tabular}{|r|l|}
\hline Journal: & International Journal of Production Research \\
\hline Manuscript ID: & TPRS-2007-IJPR-0510 \\
\hline Manuscript Type: & Original Manuscript \\
\hline Author: & 06-Jul-2007 \\
\hline & $\begin{array}{l}\text { Complete List of Authors: } \\
\text { Eroduzionomia dell'Azienda } \\
\text { Maisano, Domenico; Politecnico di Torino, Dip. Sistemi di } \\
\text { Produzione e Economia dell'Azienda } \\
\text { Mastrogiacomo, Luca; Politecnico di Torino, Dip. Sistemi di } \\
\text { Produzione e Economia dell'Azienda }\end{array}$ \\
\hline Keywords: & $\begin{array}{l}\text { SENSORS, CMM, DISTRIBUTED MANUFACTURING CONTROL, CIM, } \\
\text { PRECISION ENGINEERING }\end{array}$ \\
\hline Keywords (user): & wireless sensor networks, mobile measuring system \\
\hline & \\
\hline
\end{tabular}

\section{s) ScholarONE" \\ Manuscript Central}




\title{
Mobile Spatial coordinate Measuring System (MScMS) - Introduction to the system
}

Fiorenzo Franceschini, Maurizio Galetto, Domenico Maisano, Luca Mastrogiacomo

\author{
POLITECNICO di TORINO \\ Dipartimento di Sistemi di Produzione ed Economia dell'Azienda \\ Corso Duca degli Abruzzi 24, 10129 - Torino, ITALY, \\ Tel. +39011 5647225, Fax. +39011 5647299, e-mail: fiorenzo.franceschini@ polito.it
}

\section{Abstract}

In many industrial fields (for example, automotive and aerospace) dimensional measurements of large size objects should be easily and rapidly taken. Nowadays, the problem can be handled using many metrological systems, based on different technologies (optical, mechanical, electromagnetic etc..). Each of these systems is more or less adequate, depending on measuring conditions, user's experience and skill, or other factors like time, cost, dimensions, accurateness, portability etc.. In general for measuring medium-large size objects, portable systems can be preferred to fixed ones. Transferring the measuring system to the measured object place is often more practical than the vice-versa

The purpose of this paper is to introduce a new system called Mobile Spatial coordinate Measuring System (MScMS). The system has been designed to perform dimensional measurements of medium-large size objects. MScMS is made up of three basic parts: a "constellation" of wireless devices, liberally distributed around the working area; a mobile probe to register the coordinate points of the measured object; a PC to store data sent by the mobile probe - via Bluetooth - and to elaborate process them by means of an ad hoc application software. MScMS is easily adaptable to different measuring environments and does not require complex procedures for installation, start-up or calibration.

This document presents the system hardware/software/firmware architecture and functionalities and describes the peculiarities and metrological performances of MScMS first prototype, which has been developed at the industrial metrology and quality laboratory of DISPEA - Politecnico di Torino.

The final section illustrates the most critical aspects of MScMS and the research perspectives for future improvements

Keywords: mobile measuring system, wireless sensor networks, dimensional measurements, coordinate measuring machine (CMM). 


\section{Introduction}

This paper introduces a new measuring system called Mobile Spatial coordinate Measuring System (MScMS). MScMS is designed to perform simple and rapid dimensional measurements of large size objects. An essential requirement for the system is portability that is its aptitude to be easily transferred and installed.

Many types of metrological equipments, utilizing different kind of technologies (optical, mechanical, electromagnetic etc..), give physical representations of measured objects in a three-dimensional Cartesian Coordinate System. Coordinate Measuring Machines (CMM), theodolites / tacheometers, photogrammetry equipments, GPS (Global Positioning Systems), laser-trackers are typical instruments to do it. Each of these systems is more or less adequate, depending on measuring conditions, user's experience and skill, and other factors like time, cost, size, accuracy, portability etc.. Classical CMMs that make possible performing repeated and accurate measurements on objects which are even complexly shaped are widespread. On the other hand, CMMs are generally bulky and not always suitable for measuring large size objects (for example, longerons of railway vehicles, airplane wings, fuselages etc..), because the working volume is limited [ISO 10360, part 2 - 2001]. In general, for measuring mediumlarge size objects, portable systems can be preferred to fixed ones. Transferring the measuring system to the measured object place is often more practical than the vice-versa[Bosch 1995]. Systems as theodolites/tacheometers, photogrammetry equipments, laser-trackers, or GPS - rather than CMMs - can be easily installed and moved [Pozzi - 2002]. However, they can have some other drawbacks as mentioned in the next section.

MScMS have been designed to be portable, easy to install and start-up, low priced and adequate for measuring medium-large size objects. Innovative measuring systems, which have been recently industrialised, only partially fulfil previous desiderata. In particular, we mention 3rd Tech Hi Ball, Leica T-Probe and Metris Laser Radar [Welch et al. - 2001; Rooks - 2004; www.metris.com]. These systems - allbased on optical technologies - are lightweight and very accurate, but they are relatively high priced and generally require large time for installation and start-up.

Before introducing MScMS, in the next section we provide a structured description of requirements and functionalities that a generic system should meet. At the same time, we present a taxonomy of the most common techniques and metrological equipments for dimensional measuring. Major advantages and drawbacks will be highlighted. The attention will be subsequently focusd on MScMS . The following aspects will be analysed in detail: 
hardware and software configuration; MScMS description and description of the first prototype; trial runs and preliminary experimental results; critical aspects and possible improvements.

The final section of the document illustrates possible improvements and research perspectives for MScMS enhancement.

\section{System requirements and comparison with other measuring techniques}

MScMS has been designed to perform dimensional measurements of medium-large size objects - dimensions up to $30 \div 60$ meters. It should be easy to move and install, low-priced and able to work indoor (inside warehouses, workshops, laboratories). Tab. 1 identifies MScMS basic requirements

\section{Please, insert Tab.1}

Considering previous requirements, we briefly analyse the most common measuring tools and techniques. Tab. 2 shows the result of a qualitative comparison among 5 measuring instruments: theodolite/tacheometer, CMM, laser-tracker, photogrammetry system, and GPS. The last row of the table takes account of MScMS target performances.

\section{Please, insert Tab.2}

Different considerations rise from Tab. 2. CMMs - in spite of being very accurate measuring instruments - are expensive, bulky and not easily movable. On the other hand, theodolites or GPS are smaller and lightweighter but not very flexible, in terms of different types of measurements offered. Furthermore, GPS systems are less accurate, and cannot operate indoor. Interferometrical laser trackers and digital photogrammetry equipments are extremely accurate, but complex and expensive at the same time [Sandwith, Predmore - 2001]. Points to be measured need to be identified by the use of reflective markers or projected light spots. Theodolites/tacheometers are typically used in topography, but are not suitable to measure complex shaped objects.

In conclusion, none of the examined measuring systems fulfil all previous requirements. MScMS is a system based on the wireless sensor network technology, able to make a tradeoff among these requirements. 


\section{MScMS hardware equipment}

MScMS is made up of three basic parts:

1) a "constellation" of wireless devices, distributed around the measuring area;

2) a mobile probe to register the coordinates of the object "touched" points;

3) a PC to store data sent - via Bluetooth - by the mobile probe and an ad hoc application software.

The mobile probe is equipped with two wireless devices, identical to those making up the constellation. These devices, known as Crickets, are developed by Massachusetts Institute of Technology and Crossbow Technology. They utilize two ultrasound (US) transceivers in order to communicate and evaluate mutual distances [MIT C.S.A.I.L. - 2004].

The system makes it possible to calculate the position - in terms of spatial coordinates - of the object points "touched" by the probe. More precisely, when a trigger mounted on the mobile probe is pulled, current coordinates of the probe tip are sent to a PC via Bluetooth. Acquired data are then available for different types of elaboration (determination of distances, curves or surfaces of measured objects).

Constellation devices (Crickets) operate as reference points, or beacons, for the mobile probe. Spatial location of the constellation devices follows a semi-automatic procedure, described on section 5.4. Constellation devices are distributed without constraint around the object to measure. In the following subsections, we describe the MScMS hardware, focusing on:

- wireless devices (Crickets);

- measuring method to evaluate mutual distances among Crickets;

- mobile probe and procedure to locate "touched" points.

\section{Please, insert Fig.1}

\subsection{Cricket devices}

Cricket devices are equipped with radiofrequency (RF) and ultrasound (US) transceivers. Working frequencies are respectively $433 \mathrm{MHz}$ (on RF) and $40 \mathrm{kHz}$ (on US). Cricket devices are developed by Massachusetts Institute of Technology and manufactured by Crossbow Technology. Each device uses an Atmega 128L microcontroller operating at 7.4 Mhz, with 8 kBytes of RAM, 128 kBytes of FLASH ROM (program memory), and 4 kBytes of EEPROM (as mostly read-only memory). Alimentation is provided by two "AA" batteries of $1.5 \mathrm{~V}$ [Balakrishnan et al. - 2003]. 


\section{Please, insert Fig.2}

Cricket devices are quite small (see Error! Reference source not found.) easy to be moved, and cheap (each unit would cost is about $10 \div 20$, if mass produced). Due to these characteristics, they are optimal for $a d-h o c$ wireless sensor network applications [Priyantha et al. -2000$]$.

Crickets are equipped with US transceivers (quartz crystals) which transform electric energy in acoustic, and vice-versa (piezo-electric effect). They generate/receive $40 \mathrm{kHz}$ ultrasound waves. Transducers excited by electric impulses, vibrate at the resonance frequency producing acoustic ultrasound impulses [ANSI/IEEE Std. 176-1987 - 1988].

\subsection{Evaluation of distances between Cricketdevices}

Crickets devices continuously communicate each other in order to evaluate mutual distances. Devices communication range is typically 8-10 meters, in absence of interposed obstacles.

The technique implemented by each pair of Crickets to estimate mutual distance is known as Time Difference of Arrival (TDoA). It is based on the comparison between the propagation time of two signals with different speed (RF and US in this case) [Savvides, Han, Strivastava - 2001]. TDoA technique is described as follows

(a) At random time intervals, included between 150 and 350 milliseconds, each device transmits a RF query-packet to other devices within its communication range, It checks if neighbouring crickets are ready to receive a US signal (Error! Reference source not found.-a) [Priyantha et al. - 2000].

(b) Ready devices reply sending a RF acknowledgement authorizing next signals transmission (Error! Reference source not found.-b).

(c) Querying Cricket is now authorized to concurrently send a RF and US signal (Error! Reference source not found.-c).

\section{Please, insert Fig.3}

(d) Receiving device measures the lapse time between reception of RF and US signals (see Error! Reference source not found.).

\section{Please, insert Fig.4}

The distance between two devices is calculated by the following formula: 


$$
\mathrm{d}=\frac{\Delta \mathrm{t}}{\frac{1}{\mathrm{~s}}-\frac{1}{\mathrm{c}}}
$$

where $\mathrm{c}$ is the speed of electromagnetic radiations, $\mathrm{s}$ the speed of sound, and $\Delta \mathrm{t}$ is TDoA [Gustafsson, Gunnarsson - 2003].

Since the large difference between c (about $300000 \mathrm{~km} / \mathrm{s}$ ) and s (about $340 \mathrm{~m} / \mathrm{s}$ in air with $\mathrm{T}=$ $20^{\circ} \mathrm{C}$ and $\left.\mathrm{RH}=50 \%\right)$ :

$$
\mathrm{d} \approx \mathrm{s} \cdot \Delta \mathrm{t}
$$

\subsection{Crickets communication}

Cricket devices build a wireless network of cooperating sensor nodes. To preserve network scalability, that is to make sure that the amount of information stored by each node is independent from network dimension (in terms of nodes), each node memorizes the distances from its direct neighbours contained in the communication range (see Error! Reference source not found.).

\section{Please, insert Fig.5}

\subsection{The mobile probe}

The Mobile probe is equipped with two Cricket devices aligned with the tip (see Error! Reference source not found.).

\section{Please, insert Fig.6}

System has been designed to be deployed over small or wide areas, depending on the dimension of measured objects. The measuring area can be "covered" varying the number of constellation nodes.

\section{MScMS software architecture}

This section describes software/firmware features of MScMS to implement the following operations:

- location of Crickets mounted on the mobile probe;

- location of points touched by the probe;

- communication and data sharing among Cricket devices;

- semi-automatic location of constellation devices. 
Error! Reference source not found. represents the first two operations. All operations are better described in the following sub-sections.

\section{Please, insert Fig.7}

\subsection{Location of Crickets mounted on the mobile probe}

Spatial location of each Cricket probe is performed using a trilateration technique. Trilateration uses the known locations of beacon reference points. To uniquely determine the relative location of a point on a 3D space, at least 4 reference points are generally needed [Chen, Cheng, Gudavalli - 2003; Sandwith, Predmore - 2001; Akcan et al. - 2006].

In general, a trilateration problem can be formulated as follows. Given a set of nodes $n_{i}$ with known coordinates $\left(\mathrm{x}_{\mathrm{i}}, \mathrm{y}_{\mathrm{i}}, \mathrm{z}_{\mathrm{i}}\right)$ and a set of measured distances $\mathrm{M}_{\mathrm{i}}$, a system of linear equations needs to be solved to calculate the unknown position of a generic point $\mathrm{P}(\mathrm{u}, \mathrm{v}, \mathrm{w})$ (see Error! Reference source not found.).

$$
\left[\begin{array}{c}
\left(\mathrm{x}_{1}-\mathrm{u}\right)^{2}+\left(\mathrm{y}_{1}-\mathrm{v}\right)^{2}+\left(\mathrm{z}_{1}-\mathrm{w}\right)^{2} \\
\left(\mathrm{x}_{2}-\mathrm{u}\right)^{2}+\left(\mathrm{y}_{2}-\mathrm{v}\right)^{2}+\left(\mathrm{z}_{2}-\mathrm{w}\right)^{2} \\
\vdots \\
\left(\mathrm{x}_{\mathrm{n}}-\mathrm{u}\right)^{2}+\left(\mathrm{y}_{\mathrm{n}}-\mathrm{v}\right)^{2}+\left(\mathrm{z}_{\mathrm{n}}-\mathrm{w}\right)^{2}
\end{array}\right]=\left[\begin{array}{c}
\mathrm{M}_{1}^{2} \\
\mathrm{M}_{2}^{2} \\
\vdots \\
\mathrm{M}_{\mathrm{n}}^{2}
\end{array}\right]
$$

If the trilateration problem is over defined ( 4 or more reference points), it can be solved using a least-mean squares approach [Savvides, Han, Strivastava - 2001].

Each unknown node (generically P) estimates its position by performing the iterative minimization of an Error Function (EF), defined as:

$$
\mathrm{EF}=\frac{\sum_{\mathrm{i}=1}^{\mathrm{n}}\left[\mathrm{M}_{\mathrm{i}}-\mathrm{G}_{\mathrm{i}}\right]^{2}}{\mathrm{n}}
$$

being:

$M_{i}$ measured distance between the $i$-th node and the unknown device (P);

$\mathrm{G}_{\mathrm{i}}$ calculated distance between the estimated position of $\mathrm{P} \equiv(\mathrm{u}, \mathrm{v}, \mathrm{w})$ and the known position of the $\mathrm{i}$-th device $\mathrm{C}_{\mathrm{i}} \equiv\left(\mathrm{x}_{\mathrm{i}}, \mathrm{y}_{\mathrm{i}}, \mathrm{z}_{\mathrm{i}}\right)$;

$\mathrm{n}$ number of constellation devices $\left(\mathrm{C}_{\mathrm{i}}, \mathrm{i}=1 \div \mathrm{n}\right)$ within device $(\mathrm{P})$ communication range.

\section{Please, insert Fig.8}


Each Cricket mounted on the mobile probe to locate its own position uses the known locations of at least four constellation Crickets, and the measured distance from them. All information needed for the location are sent to a PC, for a centralized computing.

\subsection{Location of points touched by the probe tip}

The probe tip (V) lies on the same line of devices A and B (see Error! Reference source not found.). This line can be univocally determined knowing coordinates of points $A \equiv\left(x_{A}, y_{A}\right.$, $\left.\mathrm{z}_{\mathrm{A}}\right)$ and $\mathrm{B} \equiv\left(\mathrm{x}_{\mathrm{B}}, \mathrm{y}_{\mathrm{B}}, \mathrm{z}_{\mathrm{B}}\right)$, and the distance $\mathrm{d}(\mathrm{A}-\mathrm{V})$.

The parametric equation of this line is:

$$
\left\{\begin{array}{l}
x=x_{A}+\left(x_{B}-x_{A}\right) \cdot t \\
y=y_{A}+\left(y_{B}-y_{A}\right) \cdot t \\
z=z_{A}+\left(z_{B}-z_{A}\right) \cdot t
\end{array}\right.
$$

The distance $\mathrm{d}(\mathrm{A}-\mathrm{V})$ can be expressed as:

$$
\mathrm{d}(\mathrm{A}-\mathrm{V})=\sqrt{\left(\mathrm{x}_{\mathrm{A}}-\mathrm{x}_{\mathrm{v}}\right)^{2}+\left(\mathrm{y}_{\mathrm{A}}-\mathrm{y}_{\mathrm{v}}\right)^{2}+\left(\mathrm{z}_{\mathrm{A}}-\mathrm{z}_{\mathrm{v}}\right)^{2}}
$$

Coordinates of point $\mathrm{V} \equiv\left(\mathrm{x}_{\mathrm{v}}, \mathrm{y}_{\mathrm{v}}, \mathrm{z}_{\mathrm{v}}\right)$ are univocally determined solving a system of 4 equations in 4 unknown values $\left(\mathrm{x}_{\mathrm{v}}, \mathrm{y}_{\mathrm{v}}, \mathrm{z}_{\mathrm{v}}\right.$, and $\left.\mathrm{t}_{\mathrm{v}}\right)$ :

$$
\left\{\begin{array}{l}
\mathrm{x}_{\mathrm{V}}=\mathrm{x}_{\mathrm{A}}+\left(\mathrm{x}_{\mathrm{B}}-\mathrm{x}_{\mathrm{A}}\right) \cdot \mathrm{t}_{\mathrm{v}} \\
\mathrm{y}_{\mathrm{V}}=\mathrm{y}_{\mathrm{A}}+\left(\mathrm{y}_{\mathrm{B}}-\mathrm{y}_{\mathrm{A}}\right) \cdot \mathrm{t}_{\mathrm{v}} \\
\mathrm{z}_{\mathrm{V}}=\mathrm{z}_{\mathrm{A}}+\left(\mathrm{z}_{\mathrm{B}}-\mathrm{z}_{\mathrm{A}}\right) \cdot \mathrm{t}_{\mathrm{V}} \\
\mathrm{d}(\mathrm{A}-\mathrm{V})=\sqrt{\left(\mathrm{x}_{\mathrm{A}}-\mathrm{x}_{\mathrm{v}}\right)^{2}+\left(\mathrm{y}_{\mathrm{A}}-\mathrm{y}_{\mathrm{v}}\right)^{2}+\left(\mathrm{z}_{\mathrm{A}}-\mathrm{z}_{\mathrm{v}}\right)^{2}}
\end{array}\right.
$$

Replacing terms $\mathrm{x}_{\mathrm{V}}, \mathrm{y}_{\mathrm{V}}, \mathrm{z}_{\mathrm{V}}$ in the fourth equation:

$$
\mathrm{d}(\mathrm{A}-\mathrm{V})=\sqrt{\left[\mathrm{x}_{\mathrm{A}}-\mathrm{x}_{\mathrm{A}}+\left(\mathrm{x}_{\mathrm{B}}-\mathrm{x}_{\mathrm{A}}\right) \cdot \mathrm{t}_{\mathrm{v}}\right]^{2}+\left[\mathrm{y}_{\mathrm{A}}-\mathrm{y}_{\mathrm{A}}+\left(\mathrm{y}_{\mathrm{B}}-\mathrm{y}_{\mathrm{A}}\right) \cdot \mathrm{t}_{\mathrm{v}}\right]^{2}+\left[\mathrm{z}_{\mathrm{A}}-\mathrm{z}_{\mathrm{A}}+\left(\mathrm{z}_{\mathrm{B}}-\mathrm{z}_{\mathrm{A}}\right) \cdot \mathrm{t}_{\mathrm{V}}\right]^{2}}
$$

then:

$$
\mathrm{t}_{\mathrm{v}}=\frac{\mathrm{d}(\mathrm{A}-\mathrm{V})}{\sqrt{\left(\mathrm{x}_{\mathrm{A}}-\mathrm{x}_{\mathrm{B}}\right)^{2}+\left(\mathrm{y}_{\mathrm{A}}-\mathrm{y}_{\mathrm{B}}\right)^{2}+\left(\mathrm{z}_{\mathrm{A}}-\mathrm{z}_{\mathrm{B}}\right)^{2}}}=\frac{\mathrm{d}(\mathrm{A}-\mathrm{V})}{\mathrm{d}(\mathrm{A}-\mathrm{B})}
$$

The denominator of equation (5.7) is the distance $\mathrm{d}(\mathrm{A}-\mathrm{B})$ between the two Cricket devices installed on the mobile probe.

In conclusion, coordinates of the point $\mathrm{V}$ can be calculated as: 


$$
\left\{\begin{array}{l}
x_{V}=x_{A}+\left(x_{B}-x_{A}\right) \cdot \frac{d(A-V)}{d(A-B)} \\
y_{V}=y_{A}+\left(y_{B}-y_{A}\right) \cdot \frac{d(A-V)}{d(A-B)} \\
z_{V}=z_{A}+\left(z_{B}-z_{A}\right) \cdot \frac{d(A-V)}{d(A-B)}
\end{array}\right.
$$

Formulas (5.8) univocally locate point V using spatial coordinates of Crickets A and B. Distances $\mathrm{d}(\mathrm{A}-\mathrm{B})$ and $\mathrm{d}(\mathrm{A}-\mathrm{V})$ are a priori known as they depend on probe geometry.

The previous model is based on the assumption that US sensor (A and B) and probe tip (V) are punctiform geometric elements. In practice, the model is inevitably approximated because sensors A and B have non punctual dimensions (see Error! Reference source not found.). To minimize point $\mathrm{P}$ position uncertainty, the following condition should be approached: $\mathrm{d}(\mathrm{B}-\mathrm{V})<\mathrm{d}(\mathrm{A}-\mathrm{V})$ [Zakrzewski - 2003].

\subsection{Cricket Firmware}

Firmware is essential to organize RF and US communication among Cricket devices.

Firmware is written in NesC language, and works under the operating system TinyOS. NesC is derived from $\mathrm{C}$, and it is currently utilized to program MICA Mote devices (produced by Crossbow Technologies), which Crickets are derived from. NesC is object-oriented and eventbased. Programs are organized in independent modules. They interrelate themselves by means of reciprocal queries/replies [MIT C.S.A.I.L. - 2004; Moore et al. - 2004].

Error! Reference source not found. shows a schematic flow-chart of Cricket firmware.

\section{Please, insert Fig.9}

Each Cricket device performs two types of operations:

a) time of flight measurement of US signals transmitted/received from other devices. At random time intervals, included between 150 and 350 milliseconds, each device tries to synchronize itself with neighbours, in order to exchange US signals. Synchronization information are transmitted through RF packets.

b) when a Cricket receives a new distance - from a neighbour, or directly measured - stores and sends it to its neighbours by a RF packet containing a new list of inter-node distances; 
Firmware coordinates the communication among Cricket devices, making them able to cooperate and share information about inter-node distances. When the user pulls the mobile probe trigger, all information are sent (via Bluetooth) to a PC for elaborations.

\subsection{Semi-automatic location of the constellation}

Location of Cricket devices should be fast and automated as much as possible. This operation - if manually performed - is tedious and conflicting with system adaptability to different working places. As a consequence - in order to minimize human moderation - a method for a semi-automatic localization has been implemented. It is important to remark that accuracy in the localization of constellation nodes is fundamental for accuracy in the next mobile probe location [Patwari et al. - 2005; Sottile and Spirito - 2005].

Two techniques for the location of constellation devices have been designed.

\section{1st approach}

First technique consists in touching (using the mobile probe) different reference points within measuring area. It is good to select points that are easily reachable and easy to be manually located in a reference coordinate system. For example, points laying on objects with a simple and known geometry (like parallelepiped vertexes). Spatial coordinates $\left(\mathrm{x}_{\mathrm{i}}, \mathrm{y}_{\mathrm{i}}, \mathrm{z}_{\mathrm{i}}\right)$ of the distributed constellation devices are the unknown parameters of the problem. Location of each device is performed using a trilateration. To identify a new device it is necessary knowing distances from at least 4 reference points [Chen, Cheng, Gudavalli - 2003]. Error! Reference source not found.-a represents the procedure to determine distances from some reference points and a constellation Cricket. The probe tip is placed next to the point $\mathrm{P}_{2}$, with the aim of calculating the distance from Cricket B4 (point D). The following distances are known:

- $\mathrm{AD}$ and $\mathrm{BD}$ from constellation Cricket $\mathrm{B} 4$ and devices $\mathrm{A}$ and $\mathrm{B}$;

- $\mathrm{AB}$ and $\mathrm{P}_{2} \mathrm{~B}$ from devices $\mathrm{A}$ and $\mathrm{B}$ - mounted on the mobile probe - and from the device $\mathrm{B}$ and the probe tip $\left(\mathrm{P}_{2}\right)$.

To calculate distance $\mathrm{P}_{2} \mathrm{D}$, we can use Carnot Theorem (see Error! Reference source not found.-b). Applying this theorem to triangle $\mathrm{ABD}$, we obtain the following equation:

$$
\mathrm{AD}^{2}=\mathrm{AB}^{2}+\mathrm{BD}^{2}-2 \cdot \mathrm{AB} \cdot \mathrm{BD} \cdot \cos (\alpha)
$$

from which:

$$
\cos (\alpha)=\frac{\mathrm{AB}^{2}+\mathrm{BD}^{2}-\mathrm{AD}^{2}}{2 \cdot \mathrm{AB} \cdot \mathrm{BD}}
$$

applying again Carnot theorem to triangle $\mathrm{P}_{2} \mathrm{BD}$ : 


$$
\mathrm{P}_{2} \mathrm{D}^{2}=\mathrm{P}_{2} \mathrm{~B}^{2}+\mathrm{BD}^{2}-2 \cdot \mathrm{P}_{2} \mathrm{~B} \cdot \mathrm{BD} \cdot \cos (\alpha)
$$

Substituting equation (5.10) within equation (5.11) we obtain:

$$
\mathrm{P}_{2} \mathrm{D}=\sqrt{\mathrm{P}_{2} \mathrm{~B}^{2}+\mathrm{BD}^{2}-\mathrm{P}_{2} \mathrm{~B} \cdot \frac{\mathrm{AB}^{2}+\mathrm{BD}^{2}-\mathrm{AD}^{2}}{\mathrm{AB}}}
$$

Equation (5.12) makes it possible to calculate the distance from the reference point $\mathrm{P}_{2}$ to the constellation device B4 (point D).

\section{Please, insert Fig.10}

The described procedure is repeated for all reference points (i.e. $\mathrm{P}_{1} \div \mathrm{P}_{4}$ in Error! Reference source not found.). Once all required distances have been taken, a trilateration technique can be applied in order to localize each constellation Cricket.

The acquisition procedure is driven by an ad hoc software routine. Calculations are automatically performed by the central PC.

\section{2nd approach}

Second approach is an extension of the first. Previous localization approach is not adequate for constellations with a large number of Crickets, since each device needs knowing distances from at least 4 reference points. For that reason, we have implemented a semi-automatic localization technique, which uses also the information on the mutual distances among constellation Crickets. This technique is based on two steps:

i. As described for the first approach, the mobile probe is used to touch 4 reference points in order to locate 5 constellation Crickets.

ii. Subsequently, the mobile probe is used as a "ear", to receive the mutual distances of all the constellation Crickets (including the 5 which have been located). Signal gathered are sent to the PC (see Error! Reference source not found.). These information - combined with the information on the 5 located Crickets - are used to locate the whole constellation, by means of an "incremental" algorithm [Moore et al. - 2004]. This algorithm starts with a set of 5 nodes with known coordinates. Other nodes in the network determine their own coordinates using distances from them. As an unknown node obtains an acceptable position estimate, it may serve as a new reference point. This process can be incrementally applied until all nodes in the network obtain their specific coordinates. 
The procedure is driven by an ad hoc software routine. Time required for self-localization is about 1-2 minutes. Calculations are automatically performed by the central PC.

\section{Please, insert Fig.11}

Again, accuracy in constellation location influences accuracy in future measurements. The more Crickets position are affected by uncertainty, the less measurements will be accurate [Taylor et al. - 2005; Franceschini et al. - 2007]

\section{MScMS prototype}

A first prototype of MScMS has been developed at the industrial metrology and quality laboratory of DISPEA - Politecnico di Torino. It is made by the following elements:

(a) Cricket Constellation. 22 Cricket devices have been freely distributed around a measuring area, covering a volume of about $60 \mathrm{~m}^{3}$. To make their positioning easy, we used different supports, such as booms, articulated arms and tripods (see Error! Reference source not found.).

(b) Mobile Probe It is made by a metal structure containinghe following elements :

(1) two Cricket devices.

(2) a tip to "touch" the points of measured objects. Tip (V) and Cricket devices (A and B) are aligned and spaced as indicated: $\mathrm{d}(\mathrm{A}-\mathrm{B})=450 \mathrm{~mm}$ e $\mathrm{d}(\mathrm{A}-\mathrm{V})=540 \mathrm{~mm}$ (see Error! Reference source not found.).

(3) a Bluetooth transceiver connected with one of the two Cricket devices, by a RS232 serial port.

\section{Please, insert Fig.12}

(c) Personal Computer. An ad hoc application SW runs on a standard PC. In order to receive data sent by the probe, PC is equipped with a Bluetooth transceiver.

(d) Application Software. The purpose of this software is to drive the user through measurements, and to make results display efficient. Functions provided are similar to those typically implemented by CMM software packages. MScMS, likewise CMMs, makes it possible to determine the shape/geometry of objects (circumferences, cylinders, plans, cones, spheres etc..), on the basis of a set of measured surface points gathered from the mobileprobe, using classical optimization algorithms [Overmars - 1997]. 
More in detail, the software is organized into three application modules to assist the user in the following operations:

- Initialization. This is a guided procedure to switch on wireless devices (Crickets and Bluetooth adapter), and open the PC connection for data reception from the mobile probe.

- Selfl ocalization of the Constellation. This procedure is described in section 5.4 (Error! Reference source not found.-a).

- Measurements. Execution of different kinds of measurements: single points measurements, distance measurements, curves and surfaces evaluation (see Error! Reference source not found.-b, Error! Reference source not found., Error! Reference source not found.).

Measurements are taken by the probe tip. When the probe trigger is pulled, the application software calculates Cartesian coordinates of the touched point. If measurement is correctly taken, an acoustic signal is emitted. Measure results are displayed using numeric and graphical representations. Error! Reference source not found. shows some screenshots of the software main menu and sub-menus.

\section{Please, insert Fig.13}

Error! Reference source not found. and Error! Reference source not found. show some displays of the MScMS software.

Please, insert Fig.14

Please, insert Fig.15

\section{MScMS actual performances, critical aspects and possible improvements}

A preliminary prototype of MScMS has been set-up and tested, with the purpose of verifying system feasibility and to evaluate the performances. The prototype actual performance has been esimated carrying out two practical tests:

1. repeatability test: a single point within the working volume is measured repeating the measurement about 50 times, leaving the mobile-probe in a fixed position (see Error! Reference source not found.-a). The test is repeated measuring at least 20 different points 
in different areas of the working volume. For each point, we have calculated the standard deviations $\left(\sigma_{\mathrm{x}}, \sigma_{\mathrm{y}}, \sigma_{\mathrm{z}}\right)$ related to the registered Cartesian coordinates $(\mathrm{x}, \mathrm{y}, \mathrm{z})$.

2. reproducibility test: this test is similar to the previous one, with the only difference that the mobile-probe orientation is changed before each measurement, with the aim of approaching each (single) point from a different direction (see Error! Reference source not found.-b).

\section{Please, insert Fig.16}

The statistical results of these preliminary tests are reported on Tab. 3 .

\section{Please, insert Tab.3}

Let notice that $\sigma_{z}$ value is basically lower than $\sigma_{x}$ and $\sigma_{y}$, both for repeatability and reproducibility tests. This behaviour is due to the geometric configuration of the constellation devices: in general, network devices are mounted on the ceiling or at the top of the measuring area and, for this reason, they can be considered as approximately placed on a plane (XY) perpendicular to the vertical (Z) axis (see Error! Reference source not found.).

Since we have experimentally verified that the distribution of the point coordinates can be considered as normal, both for repeatability and reproducibility data, the variability range, considering a $99.7 \%$ confidence level, is given by $\pm 3 \sigma$.

Reproducibility range is an index of the instrument actual accuracy, whereas repeatability variation range is an index of the target instrument accuracy, supposing to compensate the most important causes of systematic errors.

The most critical aspects of the whole measuring system are due to US sensors. In particular:

1 - Dimensions of US transceivers;

2 - US signals are prone to different types of noises

3 - Speed of sound dependence on environmental conditions;

4 - Working volume discontinuities;

5 - Use of amplitude threshold detection at receivers.

These aspects are individually discussed in the following sub-sections.

\section{1 - Dimensions of US transceivers}

A source of uncertainty in US time-of-flight measurements is due to non punctiform US sensors. The volume of each piezo-electric crystal is about $1 \mathrm{~cm}^{3}$. As shown in Error! 
Reference source not found., it is difficult to determine the exact point of departure/arrival of a US signal exchanged between a pair of Crickets. These points are placed on the US sensors surfaces, and may vary depending on their relative position (see Error! Reference source not found.).

\section{Please, insert Fig.17}

Regarding the future, Cricket devices will be modified in order to minimize this problem, for example reducing the size of US sensors.

\section{2 - US signal are prone to different types of noises}

During measurements, the user should not obstruct US signal propagation. Two possible drawbacks may occur:

i. transmitted US signal does not reach the receiver because it is completely shielded by an obstacle;

ii. transmitted US signal diffracts and goes round interposed obstacle, reaching the receiver. In this case, path covered by US is longer than the real distance between transmitter and receiver (see Error! Reference source not found.).

\section{Please, insert Fig.18}

Case (ii) is more complicated to handle than (i). In general, it is not easy to notice possible path deflections. Probe can be prone to other types of noise, like external sources of US. For example, US produced by metal objects jingling. However, wrong distance measurements, like the ones described, can be indirectly detected and rejected. To that purpose, an effective diagnostic tool is the Error Function (EF, see Eq. 5.2) [Franceschini et al. - 2002]. This function, evaluated for both the mobile-probe devices (A and B) during localization, is an index of the bias between measured distances (evaluated by means of US transceivers) and calculated distances (on the basis of the localised position). We have experimentally verified that the minimum value of the EF is generally of the order of the tenth of $\mathrm{mm}^{2}$. When one or more measured distances are wrong - due to systematic effects - the EF minimum value "explodes" becoming 3 or 4 order of magnitude greater. In practical terms, during the location of devices A and B, if the EF minimum is included below a threshold value (say $70 \mathrm{~mm}^{2}$ ), then the position is considered to be reasonable. Otherwise, it is rejected.

\section{3 - Speed of sound dependence on environmental conditions}


Speed of sound (s) value makes it possible to turn US time of flight into a distance (formula 4.2). It is well known that the speed of sound changes with air conditions - temperature and humidity - which can exhibit both temporal and spatial variations within large working volumes. As a consequence, (s) requires to be often updated, depending on the time and the position. A partial solution to this problem is to use the temperature (T) information evaluated by embedded thermometers at the Cricket receivers and to periodically update (s) using an experimental relation $s=s(T)$ [Bohn - 1988]. As a better alternative, we implemented an optimization procedure which makes it possible to estimate, measurement by measurement, the optimum (s) value, using the following information:

- Times of flight among (at least) 4 constellation Crickets and the 2 mobile-probe Crickets (A and B);

- A standard of length for referability, given by the a priori known distance between the mobile-probe Crickets (A and B).

By an automatic optimization, we calculate the (s) value which better satisfies the previous constraints, with reference to a particular portion of the working volume. In this way, the (s) value can be recalculated for each single measurement.

\section{4 - Working volume discontinuities}

A requirement of the measuring instruments is to measure uniformly and with no discontinuities all the points within the working volume. Due to its technology, MScMS is based on a network of distributed devices, communicating through RF and US. While RF sensors communication range is almost omni-directional and up to $25 \mathrm{~m}$, US sensors have a communication range limited by "cone of visions" with an opening angle of about $80^{\circ}$ and a range of no more than $10 \mathrm{~m}$ (see Error! Reference source not found.). Signal strength outside the cone drops to $1 \%$ of the maximum value [Priyantha et al. - 2000]. It is therefore important to provide a full coverage to the area served by network devices by proper alignment of the US transmitters towards the measuring area. To increase the working volume coverage it is necessary to increase the number of network devices. In general, the best solution is mounting the network devices on the ceiling or at the top of the measuring area, as shown in Error! Reference source not found.

\section{Please, insert Fig.19}

Since for locating the mobile probe by trilateration, the mobile probe should communicate with at least 4 network devices, on the basis of practical tests, we determined that the 
coverage of a indoor working volume about 4 meters high can be achieved using about 1 network device per square meter (considering a plant layout).

\section{5 - Use of amplitude threshold detection at receivers}

To evaluate time-difference-of-arrival (TDoA), receivers can detect signals with amplitude equal or greater than a threshold value. Since US transceivers operate at $40 \mathrm{kHz}$ frequency, the time period of a complete wave cycle is $1 / 40000 \mathrm{~s}=25 \mu \mathrm{s}$. US waves are saw-tooth shaped, with a linear rise (see Error! Reference source not found.).

Considering fresh US signals at the transmitter, their amplitude may decrease depending on two basic factors:

1. attenuation: signal amplitude decreases depending on the distance covered.

2. transmitter orientation: since US transmitters are not omni-directional, signal amplitude changes depending on their orientation. In particular, the maximum signal strength is related to the direction perpendicular to the transducer surface (at the center of the "cone of vision"), while signal amplitude drops to $1 \%$ of the maximum value at $\pm 40^{\circ}$ away from it [Priyantha et al. - 2000].

The consequence of the use of amplitude threshold detection is the occurrence of errors in TDoA evaluation (see Error! Reference source not found.). However, considering that amplitude threshold value is usually about $1 / 2$ of the full amplitude signal, the range of these errors is included within $1 / 2$ of the US time period. Since the speed of sound is about $340 \mathrm{~m} / \mathrm{s}$, it is typically included between 0 and $4.5 \mathrm{~mm}$ ).

\section{Please, insert Fig.20}

\section{Conclusions}

MScMS measuring system can be considered as a complementary to CMMs. It is portable, not too much expensive, and suitable for measuring large-size objects (uneasy on conventional CMMs). MScMS is made up of three basic parts: (1) a "constellation" of wireless devices, distributed around the working area; (2) a mobile probe to register coordinate points of the measured object; (3) a PC to store and elaborate data sent - via Bluetooth - by the mobile probe.

Furthermore, MScMS is adaptable to different working environments, and does not require long installation or start-up times. Before performing measurements, constellation devices freely distributed around the measuring area - automatically locate themselves in few 
minutes. System is supported by an ad hoc software - created in Matlab - to drive user through measurements and online/offline elaborations.

Today, MScMS Achilles' heel is represented by its low accuracy, due to the use of ultrasound transceivers (non punctiform dimension, speed of sound dependence on temperature etc..). As research perspectives, all factors affecting system accuracy will be analysed and improved in detail, in order to reduce their effect.

\section{References}

Akcan, H., Kriakov, V., Brönnimann, H., Delis A. (2006) GPSFree Node Localization in Mobile Wireless Sensor Networks. In Proceedings of MobiDE'06, Chicago, Illinois, USA.

ANSI/IEEE Std. 176-1987 (1988) Standard on Piezoelectricity. American National Standards Institute, New York.

Balakrishnan, H., Baliga, R., Curtis, D., Goraczko, M., Miu, A., Priyantha, N. B., Smith, A., Steele, K., Teller, S., Wang, K. (2003) Lessons from Developing and Deploying the Cricket Indoor Location System. Preprint.

Bohn, D. A. (1988) Environmental Effects on the Speed of Sound. Journal of the Audio Engineering Society, Vol. 36, No. 4.

Bosch, J. A. (1995) Coordinate Measuring Machines and Systems, Edited by Marcel Dekker, Inc. ISBN 0-8247-9581-4.

Chen, M., Cheng, F., Gudavalli, R. (2003) Precision and Accuracy in an Indoor Localization System. Technical Report CS294-1/2, University of California, Berkeley, USA.

Franceschini, F., Galetto, M., Maisano, D., Mastrogiacomo L., (2007) A Review of Localization Algorithms for Distributed Wireless Sensor Networks in Manufacturing. Forthcoming in International Journal of Computer Integrated Manufacturing.

Franceschini, F., Galetto, M., Settineri, L. (2002) On-Line Diagnostic Tools for CMM Performance. The International Journal of Advanced Manufacturing Technology, Vol. 19, No. 2, pp. 125-130.

Gustafsson, F., Gunnarsson, F. (2003) Positioning using Time Difference of Arrival measurements. Proceedings of the IEEE International Conference on Acoustics, Speech, and Signal Processing (ICASSP 2003), Hong Kong, Vol. 6, pp. 553-556.

ISO 10360, part 2 (2001) Geometrical Product Specifications (GPS) - Acceptance and reverification tests for coordinate measuring machines (CMM).

ISO 5725 (1986) Precision of test methods - Determination of repeatability and reproducibility for a standard test method by inter-laboratory tests.

MIT Computer Science and Artificial Intelligence Lab (2004) Cricket v2 User Manual. http://cricket.csail.mit.edu/v2man.html.

Moore, D., Leonard, J., Rus, D., Teller, S. S. (2004) Robust distributed network localization with noisy range measurements. Proceedings of SenSys 2004, Baltimore, MD, pp. 50-61.

Overmars, M. H. (1997) Designing the Computational Geometry Algorithms Library CGAL, Poceedings of WACG '96, Lecture Notes in Computer Science, Springer-Verlag. 
Patwari, N., Ash, J., Kyperountas, S., Hero III, A., Moses, R., Correal, N. (2005) Locating the Nodes - Cooperative localization in wireless sensor networks. IEEE Signal processing Magazine, Vol. 22, No. 4, pp. 54-69.

Pozzi, F. (2002) Comparison of 3D Measurement Techniques in Cultural Heritage Application: User Point of View. Proceedings of the 1st International Symposium on 3D Data Processing Visualization and Transmission - IEEE Computer Society, 19-21 June, Padova, Italy, pp. 762-765.

Priyantha, N. B., Chakraborty, A., Balakrishnan, H. (2000) The Cricket Location-Support system, Proceedings of the 6th ACM MOBICOM, Boston, MA.

Rooks, B. (2004) A vision of the future at TEAM. Sensor Review, Vol. 24, No. 2, pp. 137143.

Sandwith, S., Predmore, R. (2001) Real-time 5-Micron Uncertainty with Laser Tracking Interferometer Systems using Weighted Trilateration. Proceedings of 2001 Boeing Large Scale Metrology Seminar, St. Louis.

Savvides, A., Han., C., Strivastava, M. B. (2001) Dynamic fine-grained localization in ad hoc networks of sensors. Proceedings of ACM/IEEE $7^{\text {th }}$ Annual International Conference on Mobile Computing and Networking (MobiCom'01), pp. 166-179.

Sottile, F., Spirito, M. (2006) Enhanced Quadrilateral-based Localization for Wireless Ad-hoc Networks. In Proceedings of IFIP Fifth Annual Mediterranean Ad Hoc Networking Workshop (Med-Hoc-Net 2006), June 14-17, Lipari, Italy.

Taylor, C., Rahimi, A., Bachrach, J. Shrobe, H. (2005) Simultaneous Localization, Calibration, and Tracking in an ad Hoc Sensor Network. Tech. Rep., Computer Science and Artificial Intelligence Laboratory of MIT, https://dspace.mit.edu/handle/1721.1/30541.

Welch, G., Bishop, G., Vicci, L., Brumback, S., Keller, K. (2001) High-Performance WideArea Optical Tracking The HiBall Tracking System. In Presence: Teleoperators And Virtual Environments, Vol. 10, No. 1, pp. 1-21.

Zakrzewski, J. (2003) Error and Uncertainty Reduction - Challenge for a Measuring Systems Designer. Measurement Science Review, Vol. 3, Section 1, pp. 31-34. 


\section{Tables:}

\begin{tabular}{|l|l|}
\hline \multicolumn{1}{|c|}{ Requirement } & \multicolumn{1}{c|}{ Description } \\
\hline Portability & $\begin{array}{l}\text { Easy to move, easy to assemble/disassemble, lightweight and } \\
\text { small sized. }\end{array}$ \\
\hline $\begin{array}{l}\text { Fast Installation and } \\
\text { Start-Up }\end{array}$ & $\begin{array}{l}\text { Before being ready to work, system installation, start-up or } \\
\text { calibration should be fast and not too complicated. }\end{array}$ \\
\hline Low Price & Low costs of production, installation and maintenance. \\
\hline $\begin{array}{l}\text { Metrological } \\
\text { Performances }\end{array}$ & $\begin{array}{l}\text { Appropriate metrological performances, in terms of stability, } \\
\text { repeatability, reproducibility and accuracy [ISO 5725 - 1986]. }\end{array}$ \\
\hline Working Volume & $\begin{array}{l}\text { Area covered by the instrument, should be wide enough to } \\
\text { perform measurements of large size objects (dimensions up to } \\
30 \div 60 \text { meters). }\end{array}$ \\
\hline Easy Use & $\begin{array}{l}\text { System should be user-friendly. An intuitive software interface } \\
\text { should guide the user through measurements. }\end{array}$ \\
\hline Work Indoor & $\begin{array}{l}\text { System should be able to work indoor (inside warehouses, } \\
\text { workshops, or laboratories). }\end{array}$ \\
\hline Flexibility & $\begin{array}{l}\text { System should be able to perform different measurement } \\
\text { typologies (i.e. determination of point coordinates, distances, } \\
\text { curves, surfaces etc..). }\end{array}$ \\
\hline
\end{tabular}

Tab. 1 - Definition and description of MScMS basic requirements

\begin{tabular}{|c|c|c|c|c|c|c|c|c|}
\hline \multirow{2}{*}{$\begin{array}{c}\text { MEASURING } \\
\text { SYSTEM }\end{array}$} & \multicolumn{8}{|c|}{ REQUIREMENTS } \\
\hline & Portability & $\begin{array}{l}\text { Installation } \\
\text { and Start-Up }\end{array}$ & Cost & $\begin{array}{c}\text { Metrological } \\
\text { Performances }\end{array}$ & $\begin{array}{l}\text { Working } \\
\text { Volume }\end{array}$ & Easy Use & $\begin{array}{l}\text { Work } \\
\text { Indoor }\end{array}$ & Flexibility \\
\hline THEODOLITE & $H I G H$ & FAST & LOW & LOW & LARGE & MEDIUM & YES & LOW \\
\hline CMM & LOW & SLOW & $H I G H$ & $H I G H$ & SMALL & $H I G H$ & YES & $H I G H$ \\
\hline LASER TRACKER & MEDIUM & MEDIUM & MEDIUM & $H I G H$ & LARGE & LOW & YES & MEDIUM \\
\hline PHOTOGRAMMETRY & MEDIUM & SLOW & MEDIUM & MEDIUM & MEDIUM & LOW & YES & MEDIUM \\
\hline GPS & $H I G H$ & FAST & MEDIUM & LOW & LARGE & $H I G H$ & NO & LOW \\
\hline MScMS (Purpose) & $H I G H$ & MEDIUM & LOW & MEDIUM & LARGE & $H I G H$ & YES & $H I G H$ \\
\hline & & & & & & & ;) & \\
\hline & & & & & & & ;) & \\
\hline & & & & & & & (2) & \\
\hline
\end{tabular}

Tab. 2 - Measuring systems comparison: qualitative performance evaluation

\begin{tabular}{|c|c|c|c|c|c|c|}
\hline Test & \multicolumn{3}{|c|}{ repeatability } & \multicolumn{3}{c|}{ reproducibility } \\
\hline Mean standard & $\sigma_{\mathrm{x}}$ & $\sigma_{\mathrm{y}}$ & $\sigma_{\mathrm{z}}$ & $\sigma_{\mathrm{x}}$ & $\sigma_{\mathrm{y}}$ & $\sigma_{\mathrm{z}}$ \\
\cline { 2 - 7 } deviation [mm] & 4.8 & 5.1 & 3.5 & 7.3 & 7.8 & 4.1 \\
\hline
\end{tabular}

Tab. 3 - Results of the MScMS preliminary tests 


\section{Figures:}

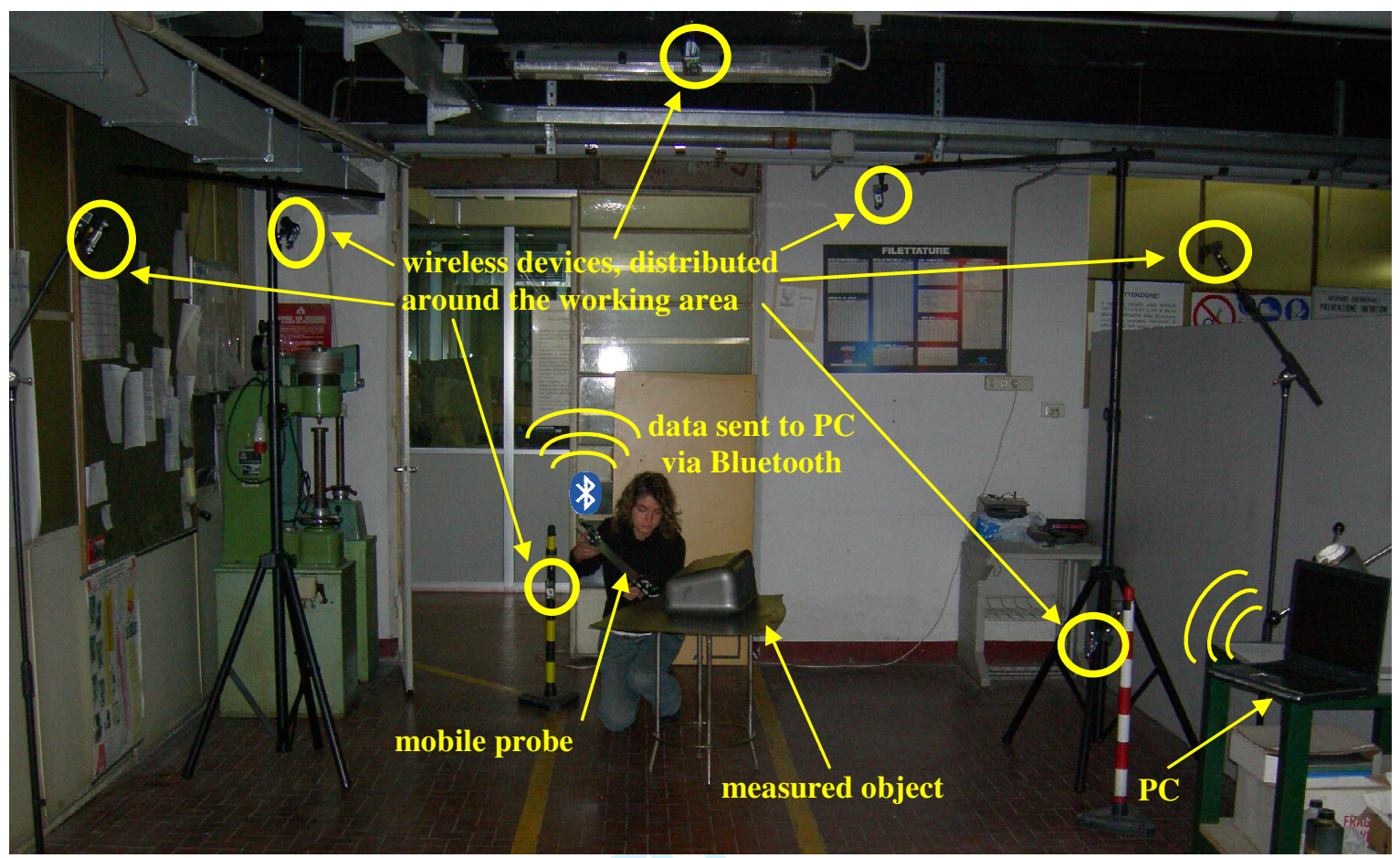

Fig. 1 - Practical application of MSCMS.

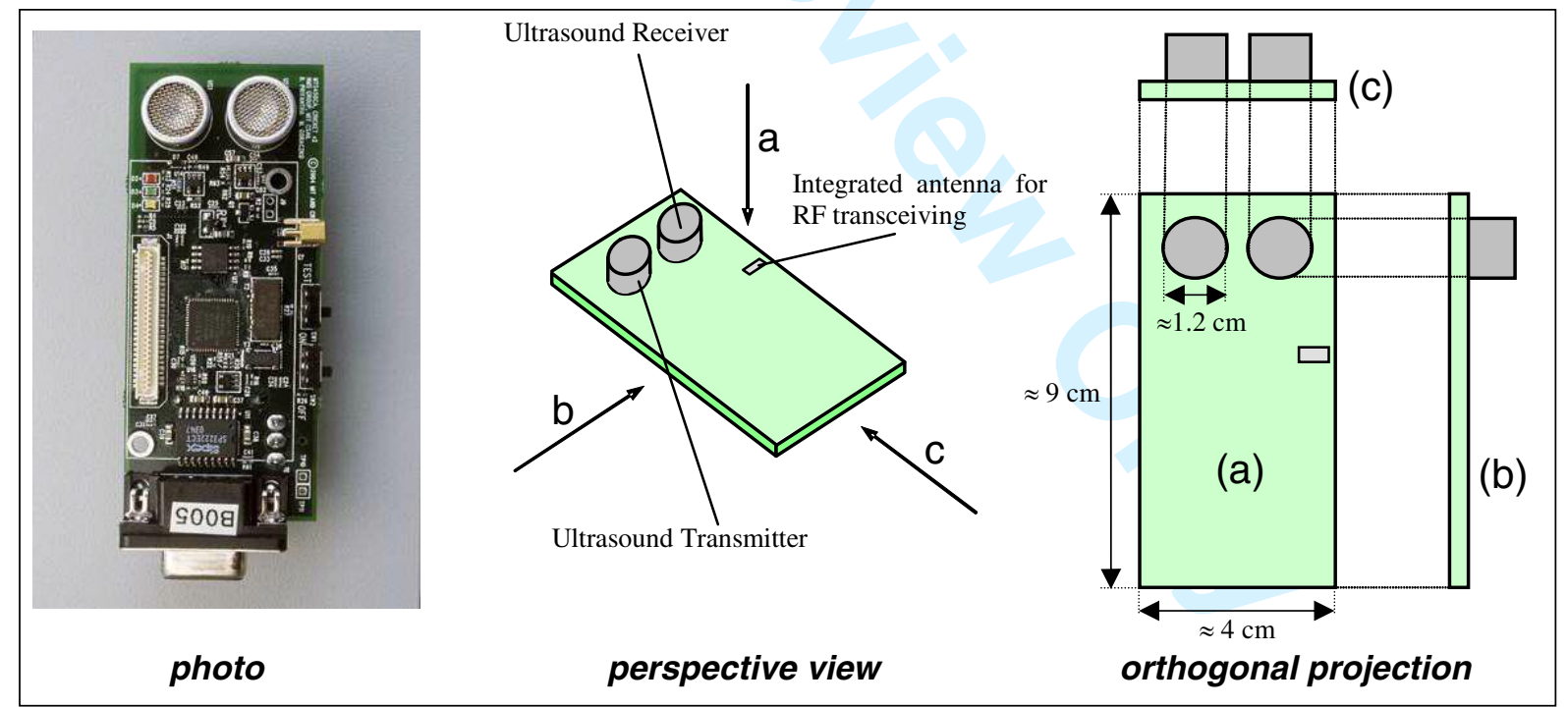

Fig. 2 - Cricket Device (Crossbow Technology). 
(a) Query (RF)

device 1

device 2
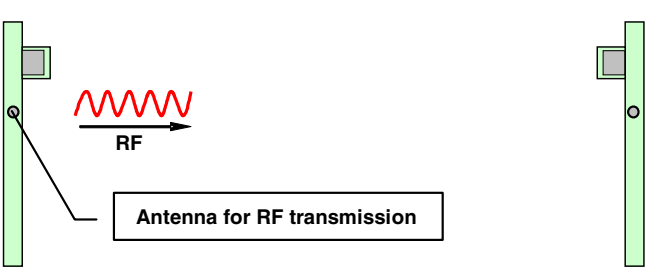

(b) Reply (RF) and authorization for signals transmission
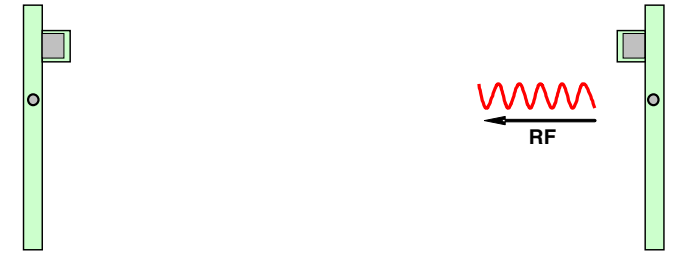

(c) Concurrent transmission of RF and US signals
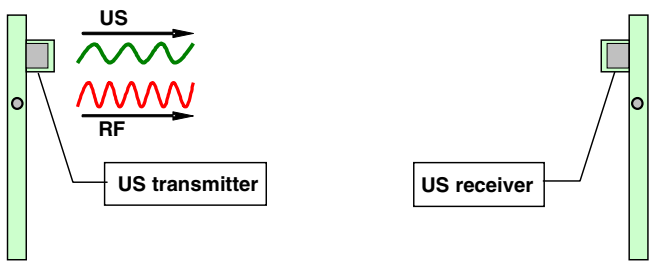

Fig. 3 - Communication scheme implemented by Cricket devices [Priyantha et al. - 2000].

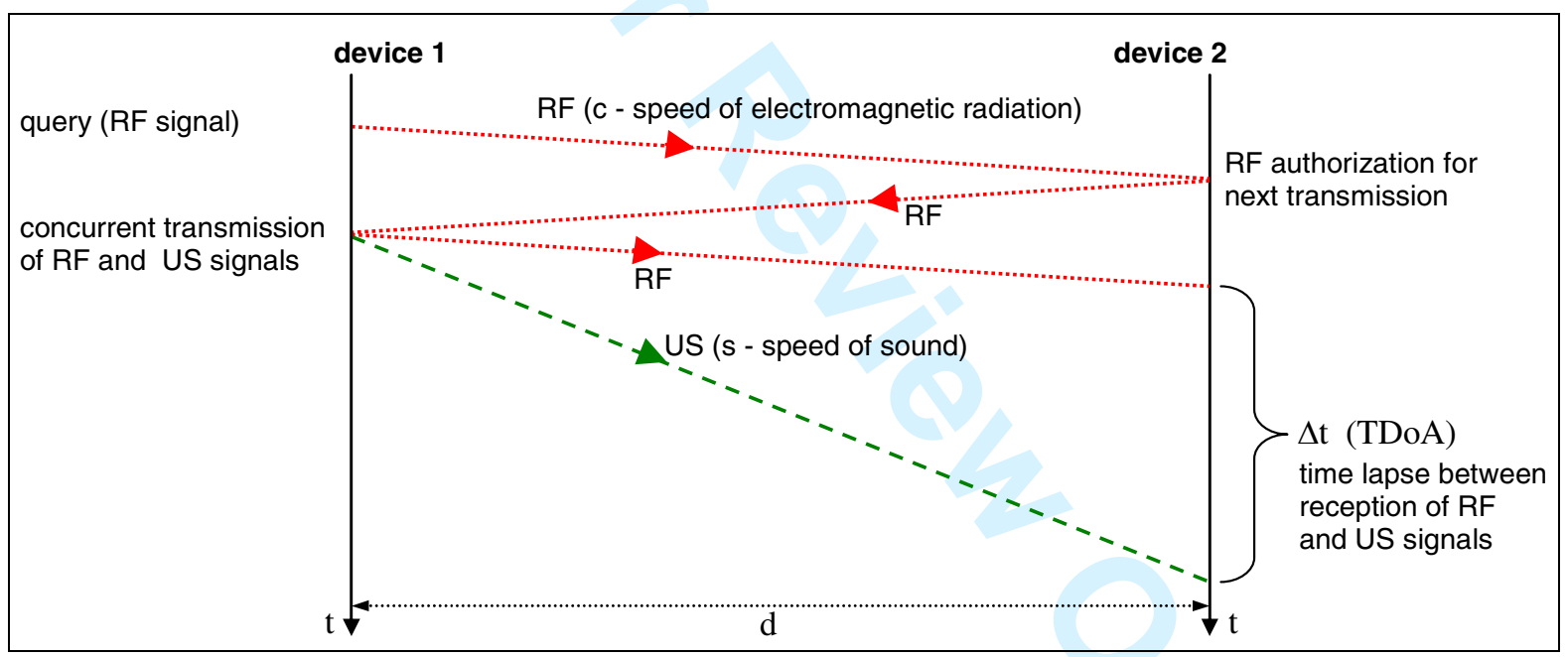

Fig. 4 - Time evolution of RF and US signals: qualitative scheme. 


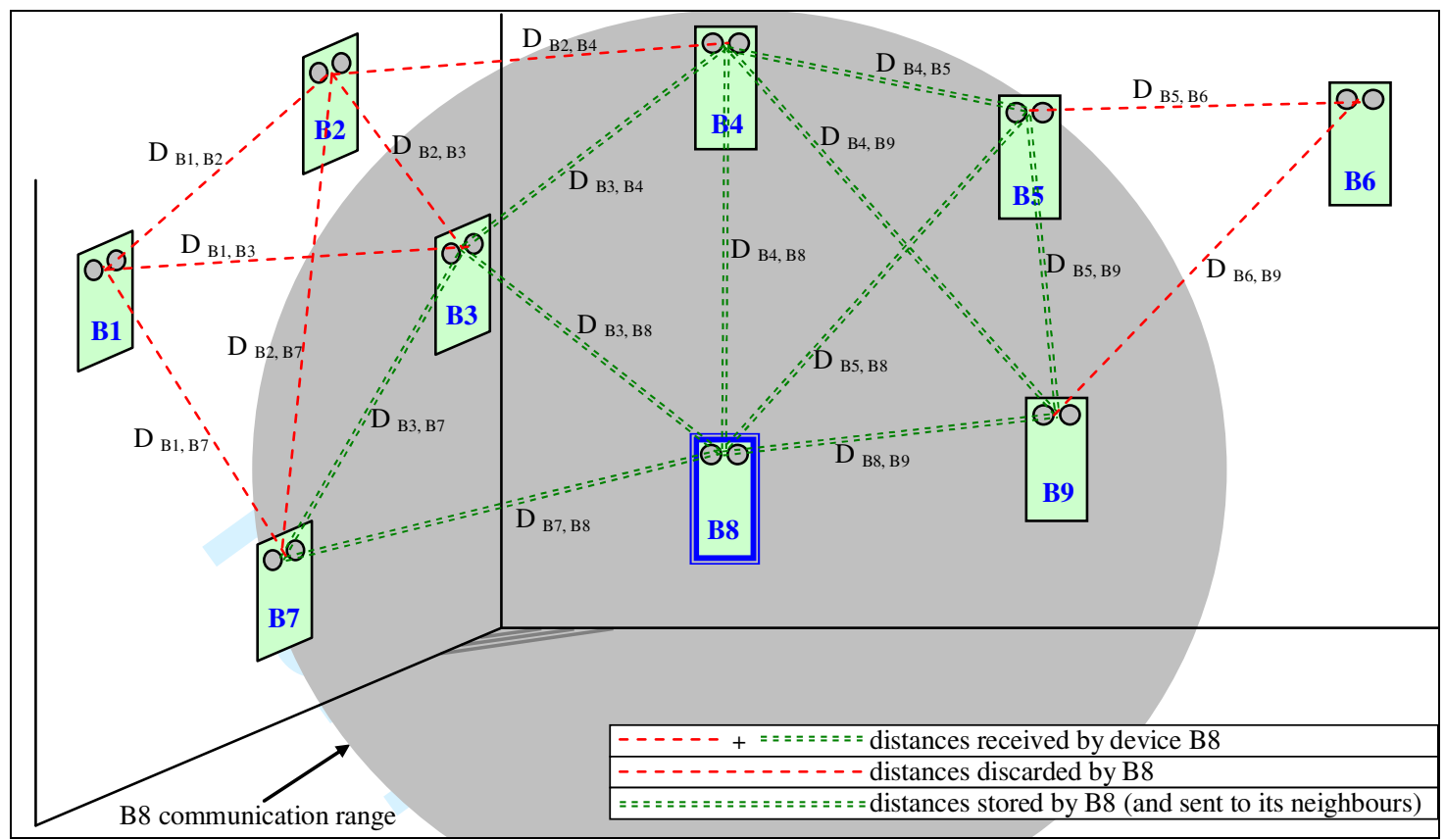

Fig. 5 - Distance information handled by a single device (B8) . The shadow highlights the B8 communication range.

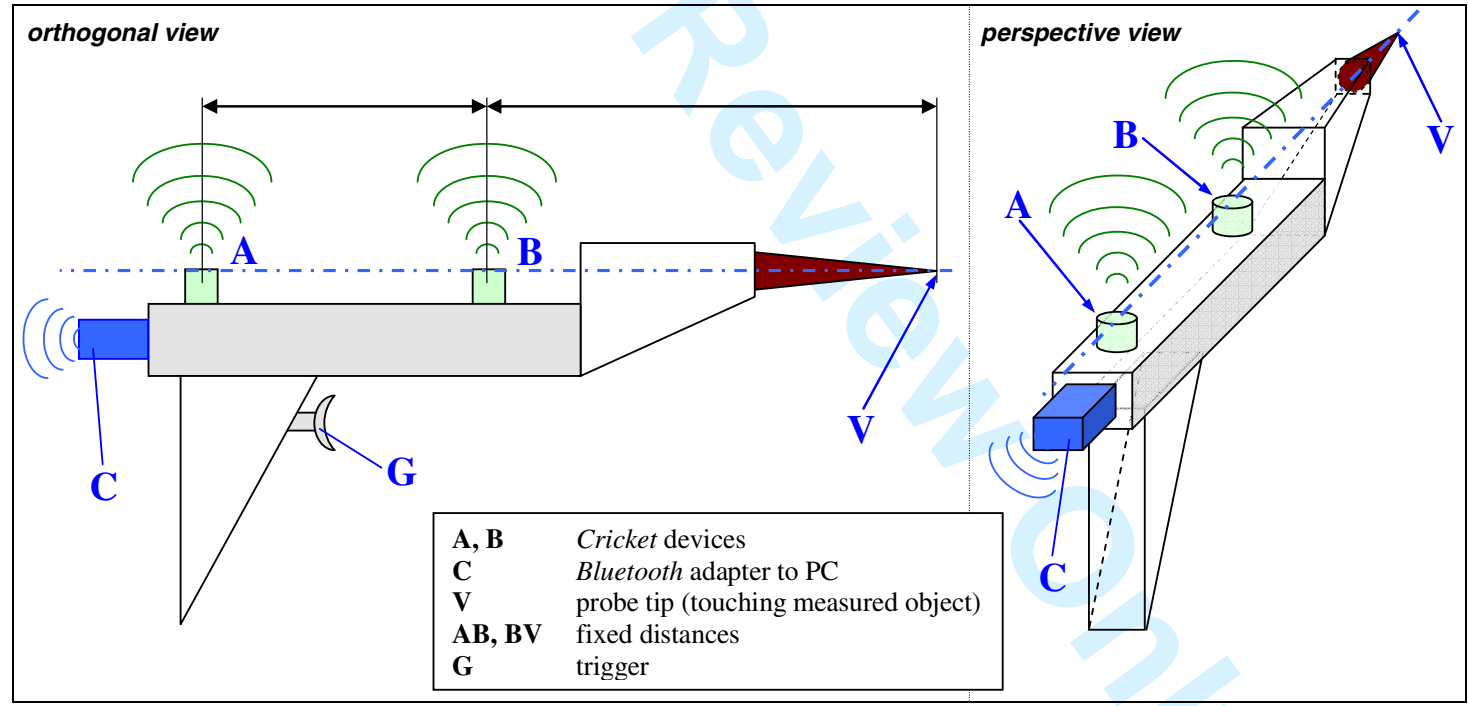

Fig. 6 - Schematic representation of the mobile probe. 


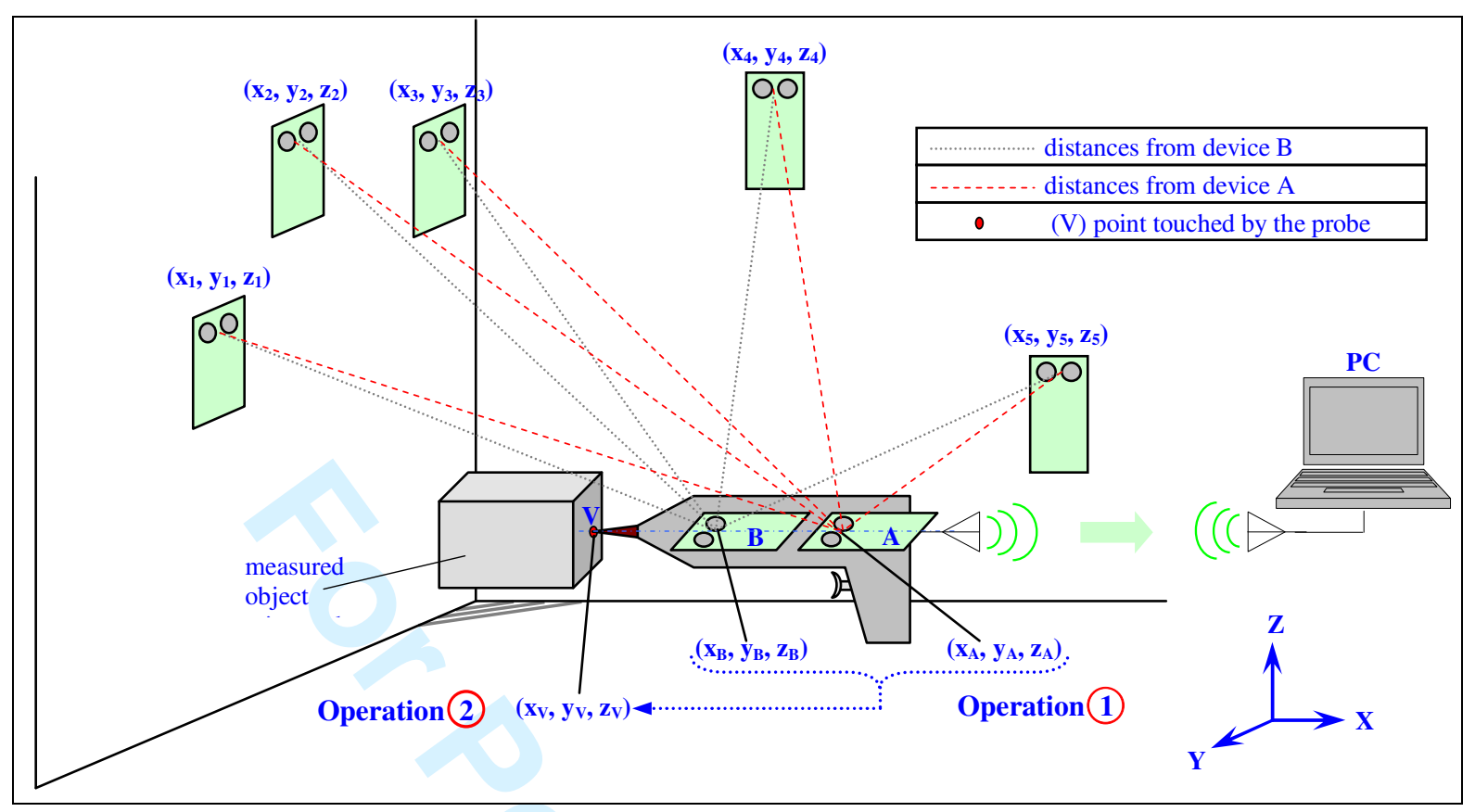

Fig. 7 - Location of points touched by the probe.

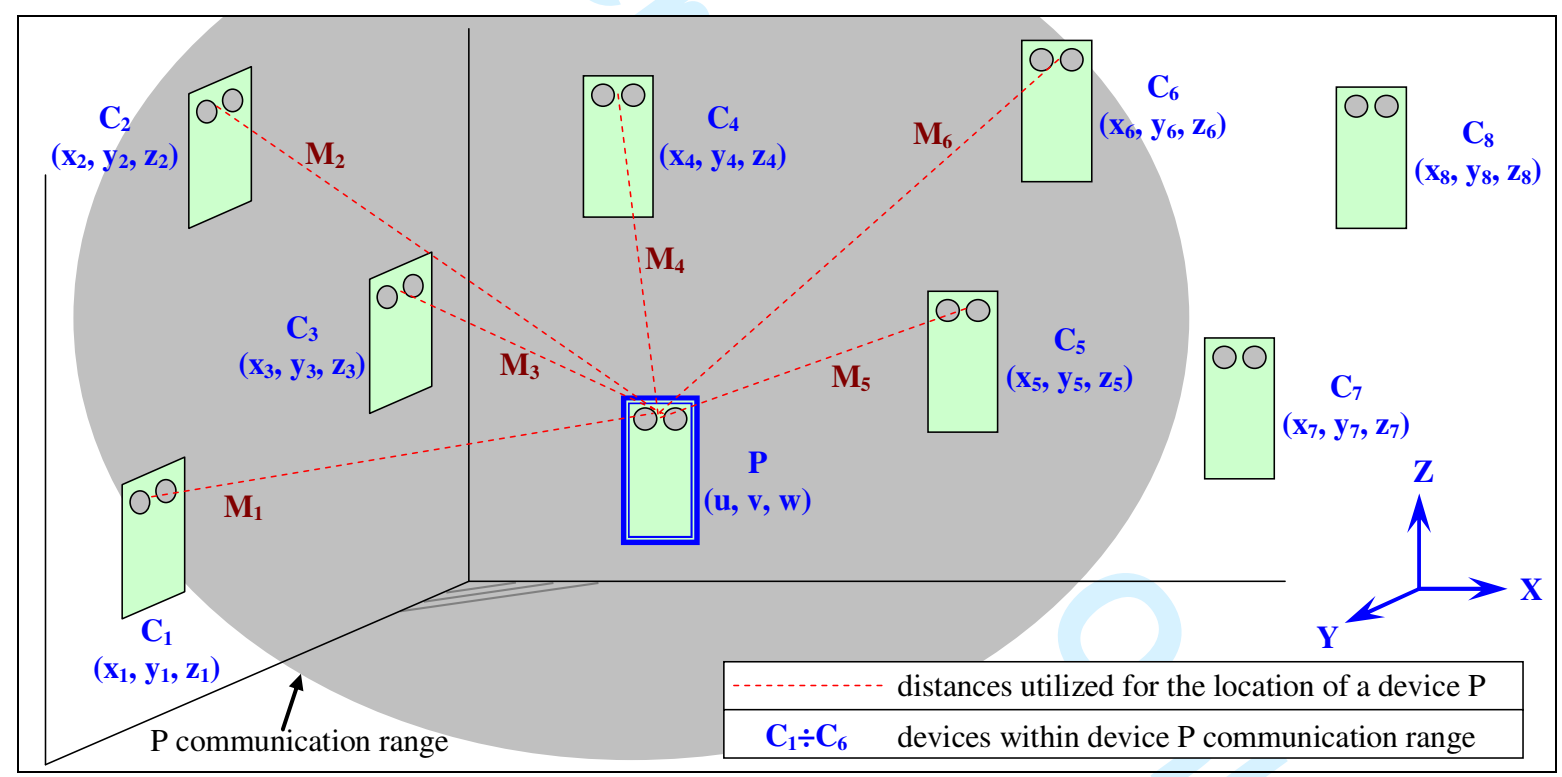

Fig. 8 - Location of a generic device $P$. 


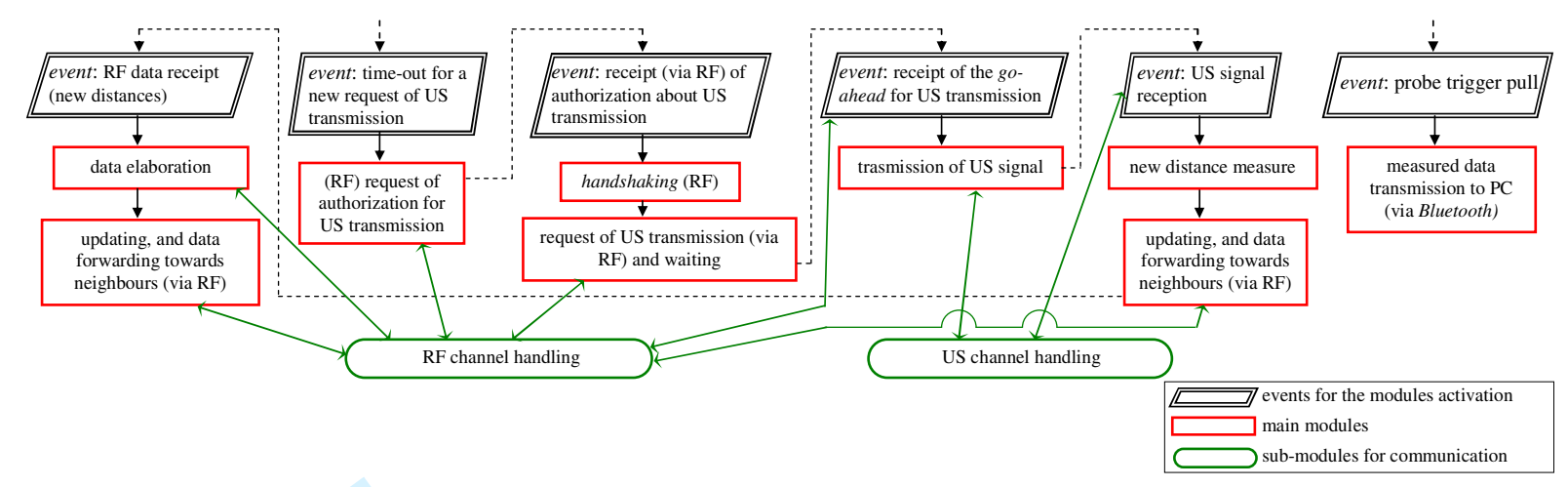

Fig. 9 - A schematic flow-chart of the Cricket firmware.

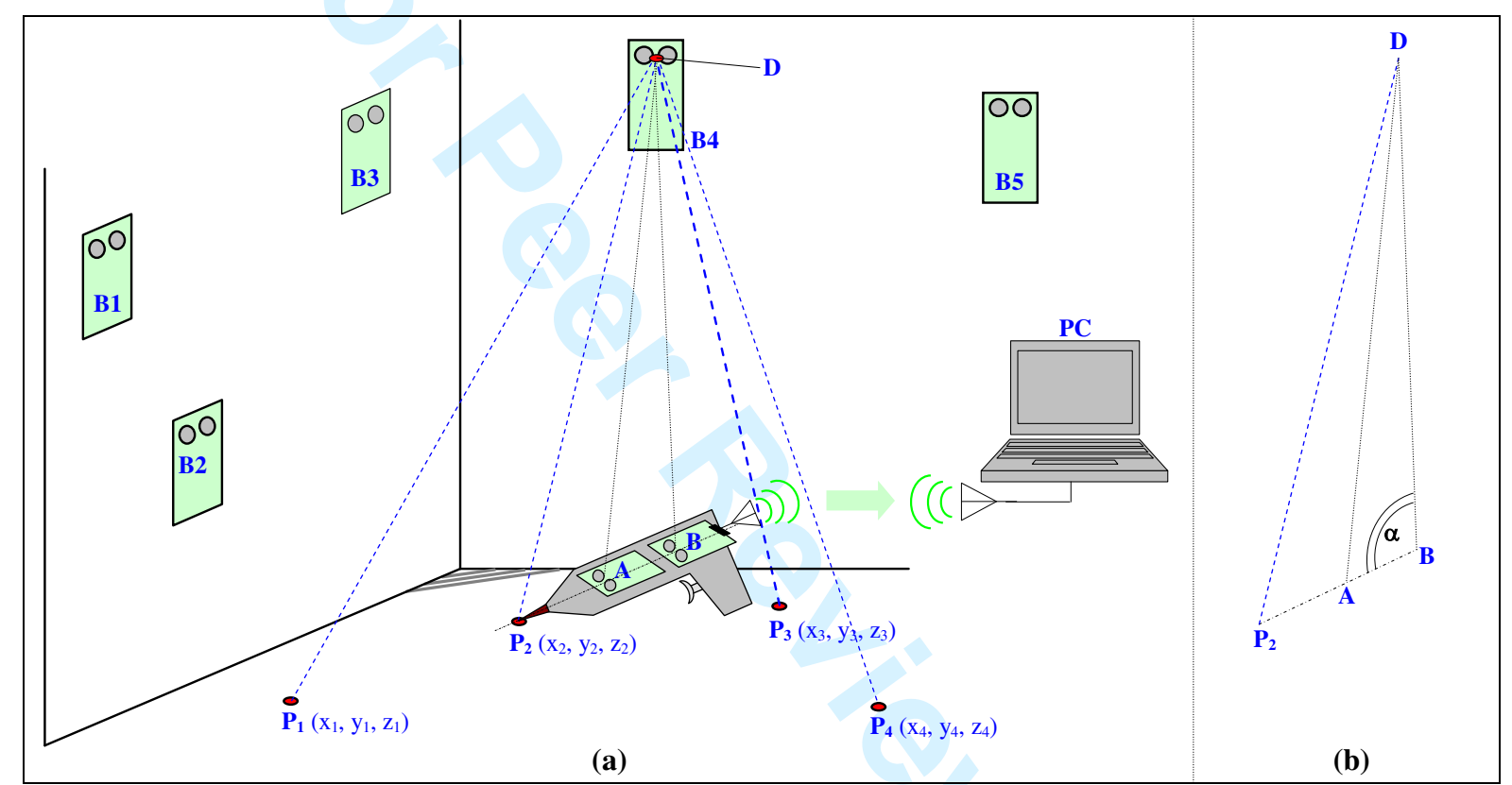

Fig. 10 - Location of constellation device $B 4$, utilising distances from $P_{1}, P_{2}, P_{3}, P_{4}$ reference points. 


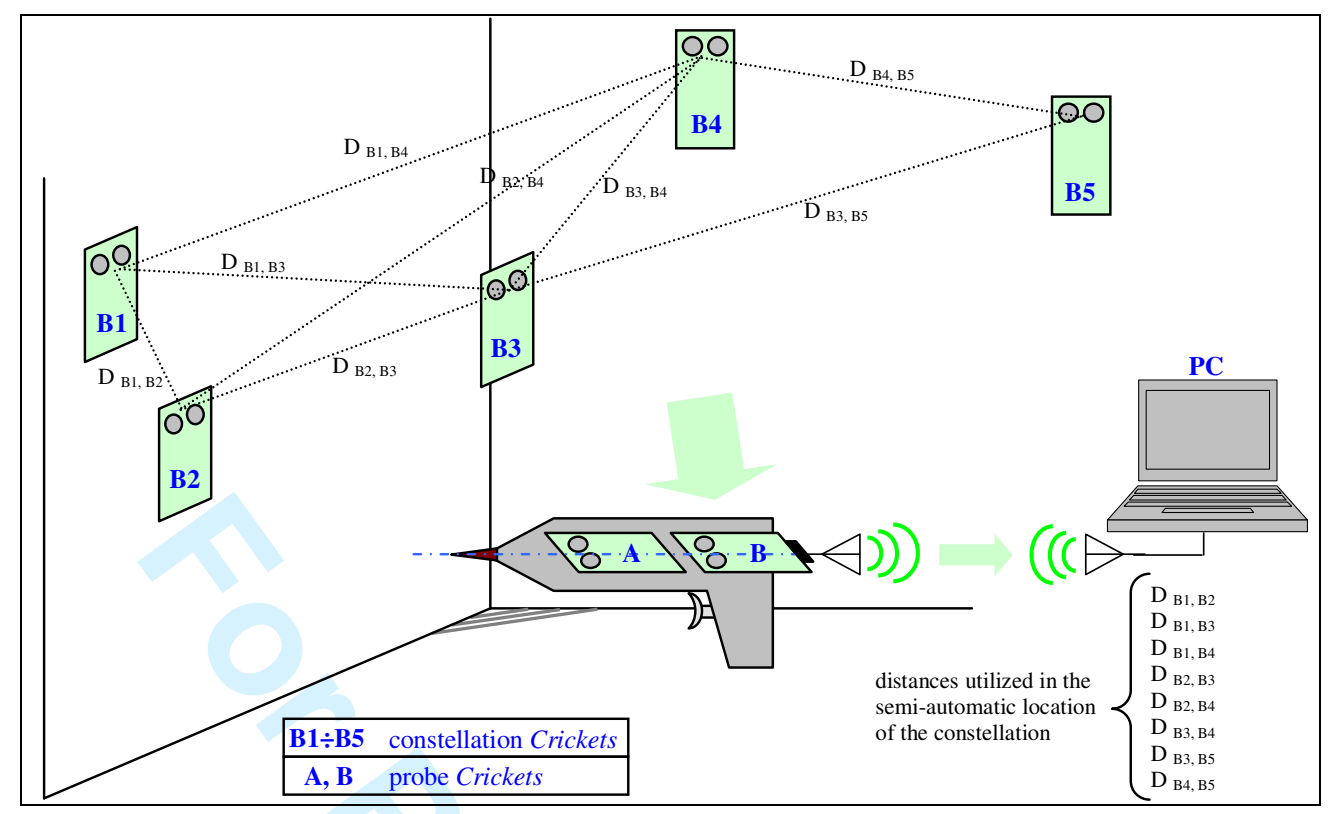

Fig. 11 - Constellation location using the mobile probe as a "ear".

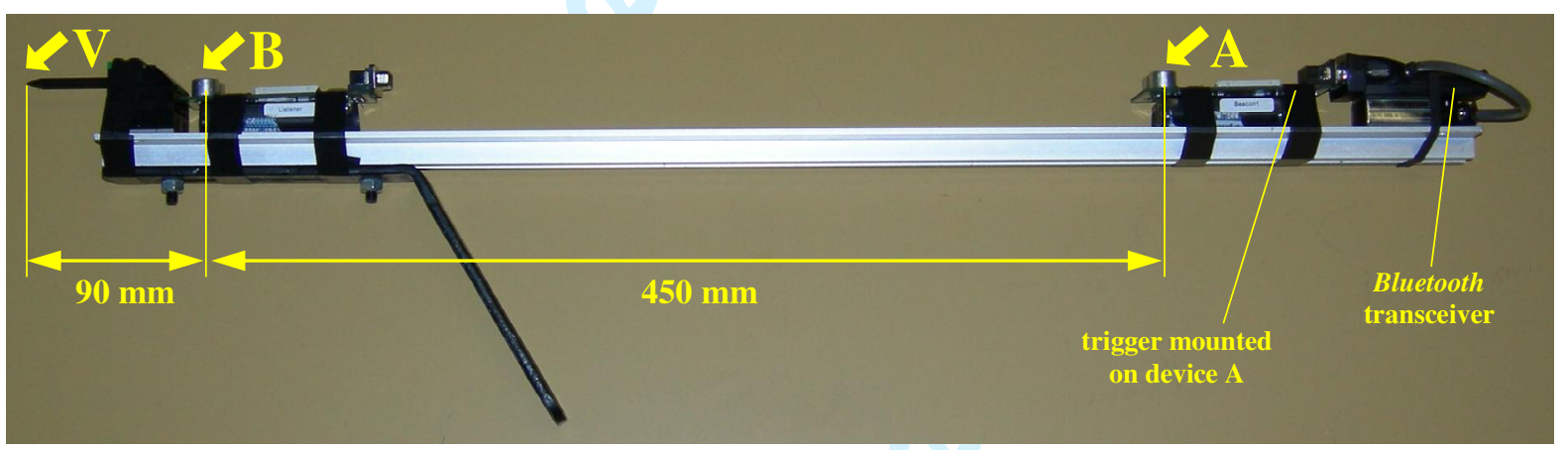

Fig. 12 - Mobile probe prototype. 


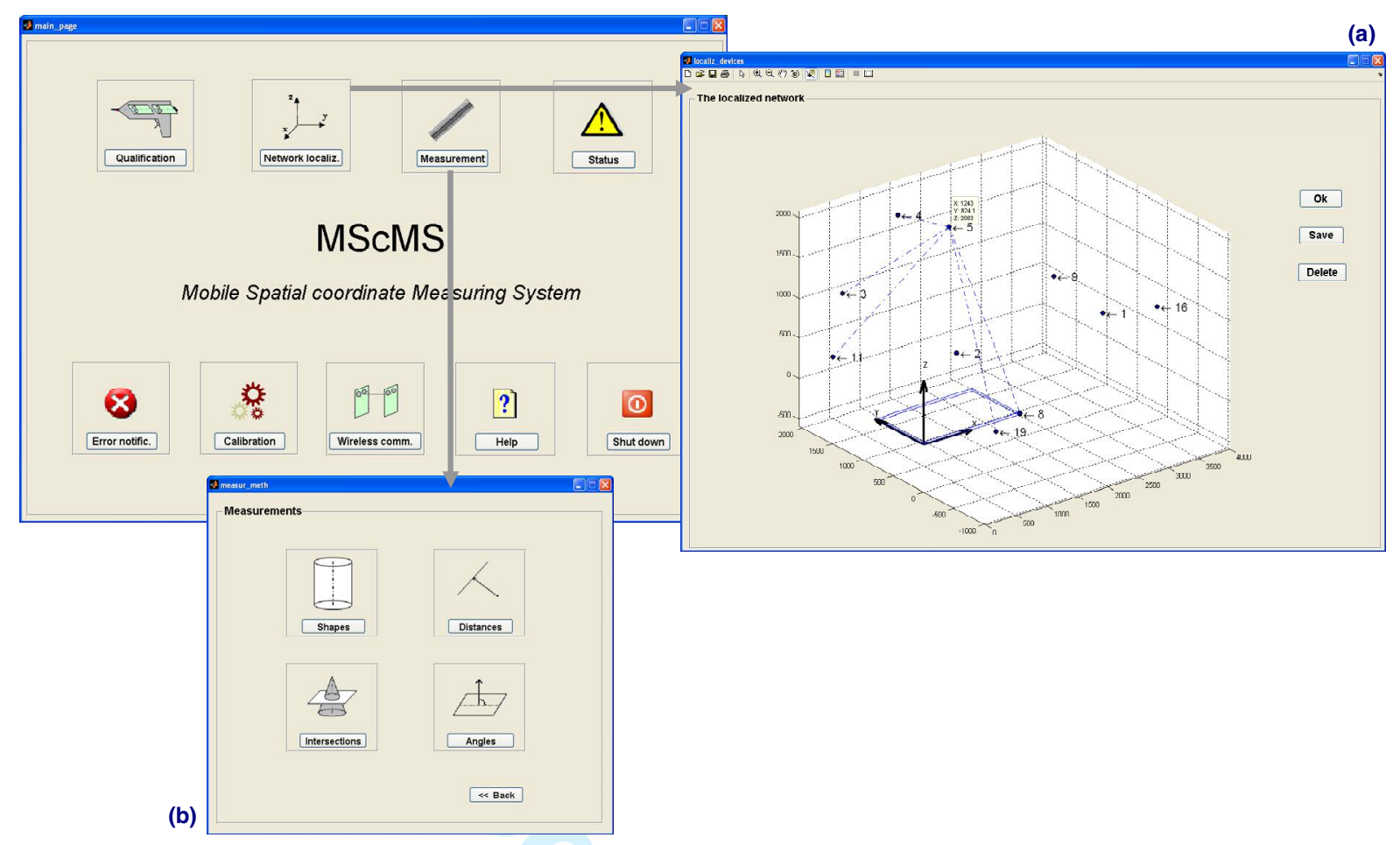

Fig. 13 - MScMS software menu.

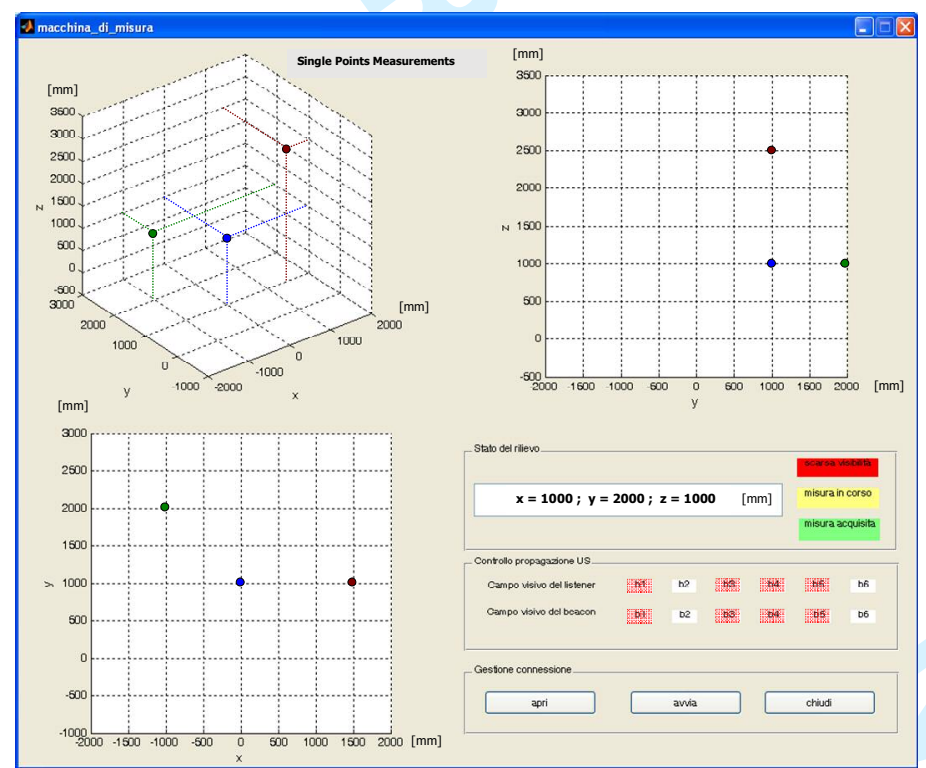

Fig. 14 - Display for the measurement of single points. 


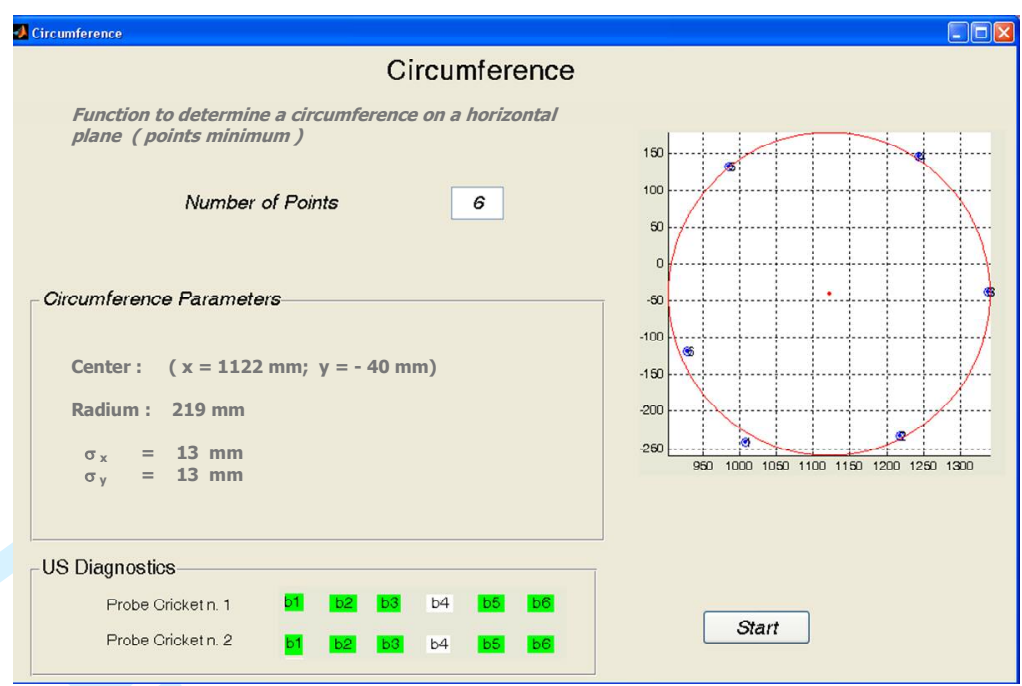

Fig. 15 - Display for the measurement of a circle.

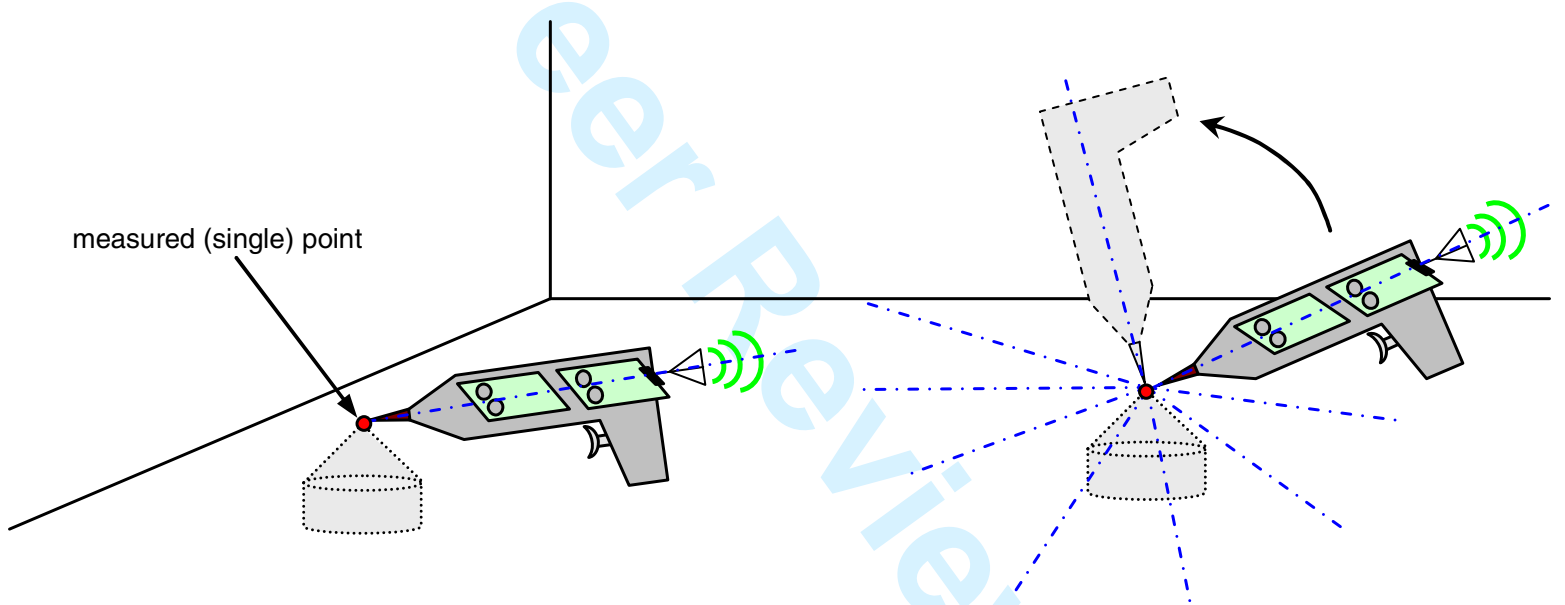

a) repeatability: the mobile-probe position is fixed during the measurements

b) reproducibility: the mobile-probe direction is changed before every measurement

Fig. 16 - Representation scheme of the practical tests carried out to evaluate MScMS performances.

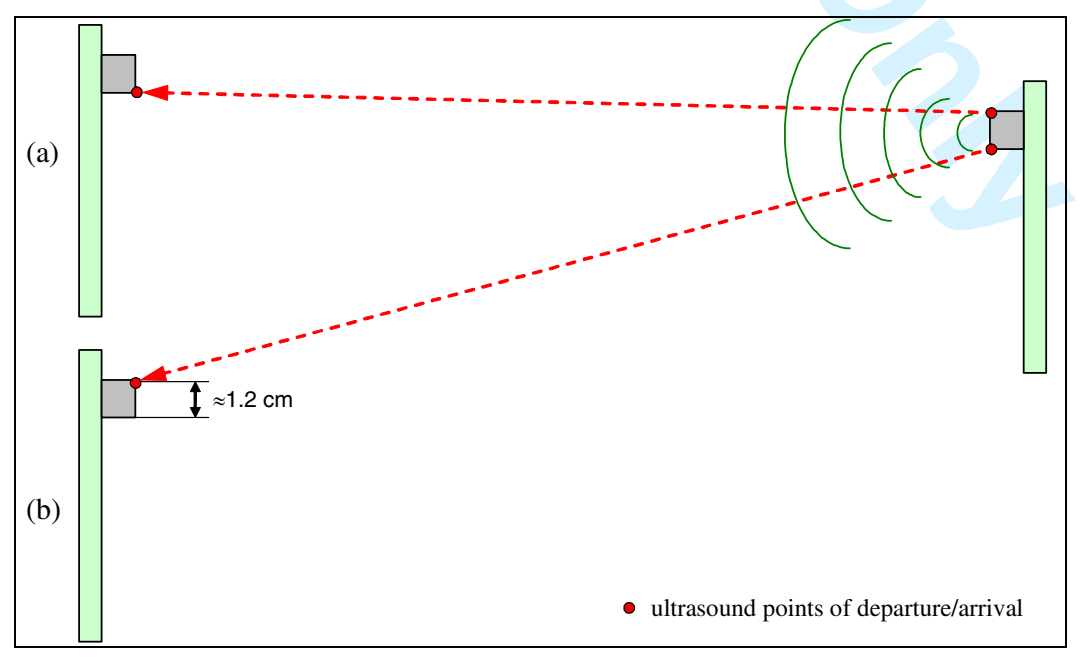

Fig. 17 - Points of departure/arrival of US exchanged between 2 Crickets. 


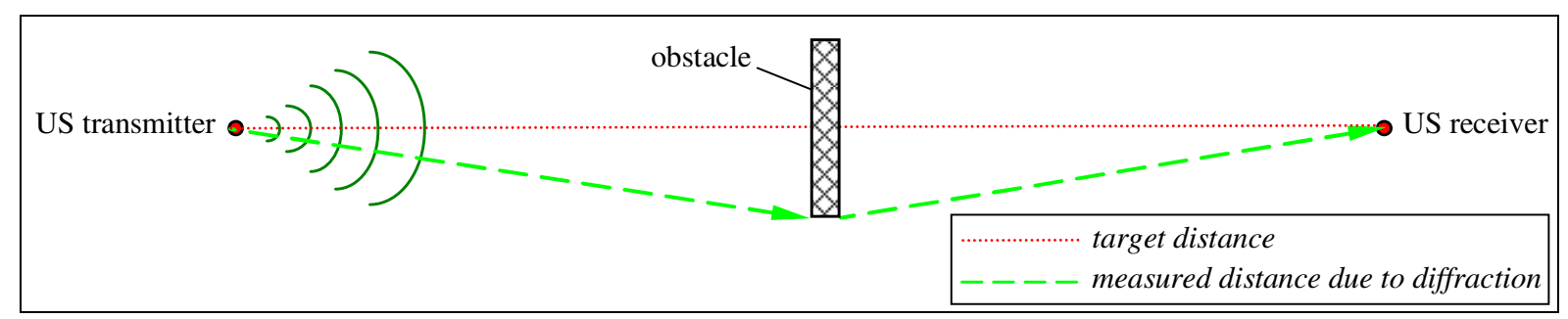

Fig. 18 - US diffraction.

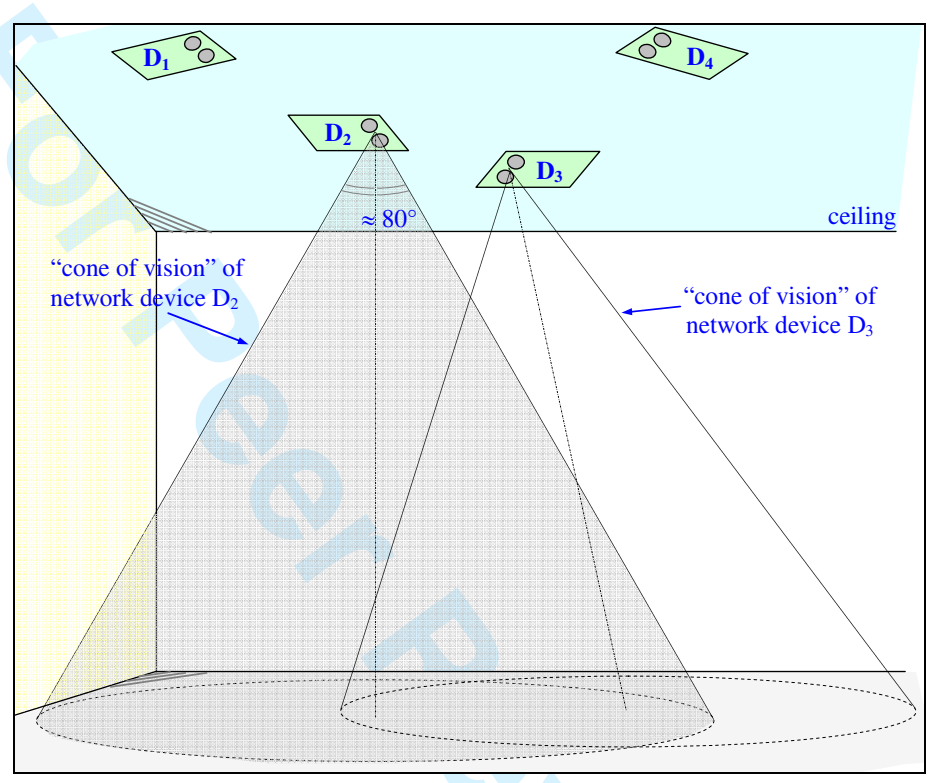

Fig. 19 - Representation scheme of the US sensors "cone of vision".

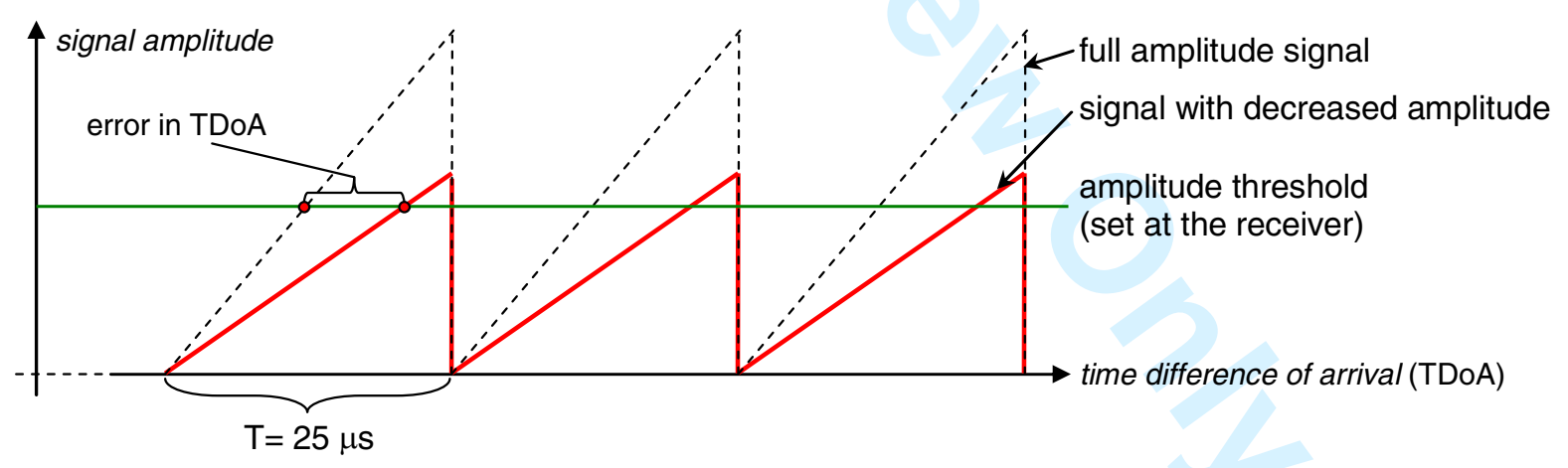

Fig. 20 - Representation scheme of the error produced by the use of amplitude threshold detection. 